\title{
Joaquim M. Bartrina, cervantista
}

\author{
FranCESC XAVIER VALl SOLAZ*
}

\begin{abstract}
Resumen
Ampliando el conocimiento del polifacetismo de Joaquim M. Bartrina, se estudian diversos trabajos o proyectos suyos sobre Cervantes, en especial su contribución al inventario de la presencia del Quijote en el teatro, y las referencias a esta novela en su producción literaria (una epístola poética imitando el poema de Urganda la Desconocida al Quijote, tres pensamientos en verso o prosa y una narración invirtiendo los estereotipos sociales de don Quijote y Sancho, desarrollada por Josep Miró i Folguera). Bartrina, manteniendo la adscripción romántica del primer personaje al ideal y del segundo a la realidad, pero desde una óptica positivista, concluye que ambos representan dos aspectos del hombre.
\end{abstract}

Palabras clave: Cervantes; Quijote; Joaquim M. Bartrina; Josep Miró i Folguera; idealismo; romanticismo; realismo; positivismo; darwinismo.

\section{Title: Joaquim M. Bartrina, Cervantist}

\begin{abstract}
Expanding the knowledge of the versatility of Joaquim M. Bartrina, this article studies his works or projects on Cervantes, especially his contribution to the inventory of the presence of Don Quixote in theatre, and the references to this novel in his literary production (a poetical epistle imitating the poem of Urganda la Desconocida to Don Quixote, three thoughts in verse or prose, and a narrative interchanging the social stereotypes between Don Quixote and Sancho, developed by Josep Miró i Folguera). Bartrina, keeping the romantic ascription of the first character to the ideal and the second one to reality, but from a positivist point of view, concludes that both represent two aspects of man.
\end{abstract}

Keywords: Cervantes; Don Quixote; Joaquim M. Bartrina; Josep Miró i Folguera; Idealism; Romanticism; Realism; Positivism; Darwinism.

* Universitat Autònoma de Barcelona. Francesc.Vall@uab.cat / ORCID iD: http://orcid.org/00000002-8521-9639. 


\section{Cómo citar este artículo / Citation}

Vall Solaz, Francesc Xavier (2019). «Joaquim M. Bartrina, cervantista», Anales Cervantinos. 51, pp. 277-312, https://doi.org/10.3989/anacervantinos.2019.013.

\section{INTRODUCCIÓN}

Joaquim M. Bartrina i d'Aixemús (Reus 1850 - Barcelona 1880), polifacético escritor que refleja la crisis del romanticismo y el auge del positivismo y del darwinismo, no es todavía suficientemente conocido, a pesar de contar ya con notables estudios ${ }^{1}$. En particular, su cervantismo, que entronca con una considerable tradición cervantista catalana, ha quedado bastante olvidado. En cambio, Enrique Rodríguez Solís (1900) reivindicó que «uno» de los «mejores amigos» de Bartrina le contó que este, «en los últimos meses pasados en la ciudad natal, no leyó más libro que Don Quijote, el único que le distraía y le interesaba, y sobre el cual hacía los más sabrosos comentarios, elogiando y admirando esta obra colosal, que estimaba como la síntesis más grande del espíritu humano»².

El 20 de septiembre de 1871 Bartrina se matriculó del primer curso de Filosofía y Letras en la Universidad de Barcelona, donde fue alumno de Manuel Milà i Fontanals ${ }^{3}$. Desde una perspectiva romántica, en sus Principios de teoría estética y literaria, Milà (1869: 261, recopilado en 1888: 159), advierte:

Mucho se desvaría con respecto a la significación del Quijote, pero no cabe dudar que hay en él algo más que la censura de los libros de caballerías y que, sin intentarlo, representó Cervantes la oposición entre los extremos del idealismo y un positivismo prosaico ${ }^{4}$.

Aunque no consta que Bartrina prosiguiese la carrera, su afán de saber le llevó a interesarse por los más diversos temas. Josep Martí i Folguera (1883),

1. Para una aproximación biobliográfica, véase Vall 2008. Algunos trabajos recientes sobre Bartrina se reseñan en Tomàs 2014 .

2. La fecha del traslado de Bartrina a Barcelona se ha situado en 1874 o 1876, pero, en cualquier caso, frecuentaba la ciudad condal antes y Reus después (Vall 2002: 115-120). El crítico musical Joaquín Marsillach (1880: 7), que conoció a Bartrina en 1877, corroboró también su interés por Cervantes.

3. Expediente guardado en el Arxiu Històric de dicha universidad; (Jorba 1989: 128; Vall 2005: 152; Gomis y Josa 2009: 51). Su hermano Francesc conoció a Milà en los primeros Jocs Florals de Barcelona, en 1859, según evoca en «A la memòria del mestre Manuel Milà i Fontanals». La Ilustració Catalana. 258, 1908, p. 349. Omito otras referencias sobre su influencia y la de su hermano Pau en Joaquim o Francesc Bartrina.

4. Actualizo la ortografía de los pasajes citados. Milà se refirió a cuestiones cervantinas en otras obras (Jorba 1984 y 1991: passim; Bastons 2004: 86; Bacardí y Estany 2006: passim). 
amigo suyo desde la infancia, pondera que, dotado «de superior inteligencia, de erudición asombrosa, de memoria extraordinaria, de exquisito sentimiento», «hablaba» «de todo» ${ }^{5}$. Bartrina ha sido muy mitificado (Cabré 2002), pero su agudeza y documentación son innegables. Incluso sus indagaciones tecnológicas responden a un buen conocimiento de la ciencia de la época (Vall 2012b).

Sus trabajos sobre literatura han sido destacados por Jorge Hunneus Gana (1889: 345-346):

Ni halló el poeta reusense en los estudios de ciencias naturales y de filosofía positiva pasto suficiente a la insaciable avidez de su espíritu, pues, no contento con los problemas de antropología, de teología, de filología y aun de historia [...], metió también la mano en graves tareas de crítica y restauración literaria, rehaciendo juiciosa, aunque ligeramente, la reputación, con tanta injusticia olvidada, del poeta y novelista español don Alonso de Castillo Solórzano ${ }^{6}$.

En 1872, en una velada del reusense Centre de Lectura en homenaje a Cervantes, Bartrina centró su alocución en el contexto literario europeo de la época, en la biografía de este escritor y en el Quijote de Avellaneda y, en 1876, en una colaboración en la revista Cervantes -la cual edito en un apéndice del presente artículo-, añadió datos sobre la presencia del Quijote en el teatro a una bibliografía de Leopoldo Rius, que, a su vez, completaba otra de José María Asensio Toledo. Bartrina era un gran aficionado a las artes escénicas y a la música (Vall 2005: 146-152) ${ }^{7}$.

5. Martí i Folguera (1874: 242-244; recogido en Rius 1895-1904: III, 456) es autor de una oda «A Cervantes», en que subraya la ascensión «desde el hombre / al infinito», lo que manifiesta que, a diferencia de Bartrina, persistió en el idealismo espiritualista. Gracias a la comunicación de Montserrat Corretger (2012: 63) en el Simposi Joaquim M. Bartrina, entre les Raons Poètiques i les Científiques, celebrado en Reus el 2 de febrero de 2001, tuve noticia de que la familia Juncosa Soulère guardaba documentos de Josep Martí i Folguera. Clotilde Juncosa, biznieta difunta de dicho escritor, que me dejó ver solamente alguna carta de Guimerà, me comentó que conservaban también documentos de Josep Miró i Folguera, pero no he podido consultar más este fondo, a pesar de haberlo solicitado reiteradamente a los descendientes.

6. Bartrina (1870a: 4 y 1881: 45) evoca que don Quijote, «reprendiendo a Sancho», «cita» al «borracho» «Juan de Esquivias», retratado en el Lisardo enamorado, de Alonso del Castillo Solórzano. Debió propiciar esta confusión la relación de Cervantes con el pueblo de Esquivias y su presencia en diversas obras suyas, en alguna de las cuales se elogia su vino (Rossell 1987; Moreno Nieto 2002), y la advertencia por don Quijote a Sancho de que sea «templado en el beber» (Cervantes 2015: 1063). A excepción de las Obras en prosa y verso, no aduciré ediciones póstumas de Bartrina si no es para citar algún comentario del editor. En el mismo año, Bartrina (1870bc) publicó dos artículos más sobre literatura castellana. En el primero, se ocupó de un mito que ha sido considerado un contrapunto al de don Quijote, el de don Juan, que en 1878 recrearía con Rossend Arús en una obra de teatro (Vall 2002: 131 y 2005: 149). Según diversos periódicos, se quería representar en el Liceo el día de difuntos de 1880, año en que murió Bartrina, pero, como consta en la segunda edición (Bartrina y Arús 1887) y corrobora la prensa, se estrenó en el Teatro Ribas, de Barcelona, el 3 de noviembre de 1885. En El Eco del Centro de Lectura. 29, 29.II.1871, p. 4, se anunció una conferencia de Bartrina sobre «Los poetas olvidados del siglo XVII».

7. Puedo añadir que Joan Goula guardaba unos ignorados versos de Bartrina improvisados para una melodía suya, reproducidos en El Día, 1.I.1894, p. 5, y que este propuso, a «un compositor reusense», una «marxa fúnebre» inspirada en la Marsellesa (Diari Català. 25, 23.VIII.1880, p. 182). 
Además, proyectó otros estudios cervantinos, que, como muchas de sus ideas, truncó la diversificación de intereses y la muerte prematura. En cuanto a su obra literaria, en una epístola poética, recreó unos versos del poema de «Urganda la desconocida» al Quijote y, en un «arabesco» y en dos pensamientos en prosa, se refirió a esta novela. Comentaré también una narración suya sobre Sancho Panza, de la que ofrezco una edición crítica en un apéndice del presente artículo, y demostraré que no la desarrolló Josep Martí i Folguera, como se ha creído, sino su primo Josep Miró i Folguera.

En definitiva, analizaré todas las noticias sobre el cervantismo de Bartrina que he podido obtener, algunas desconocidas, relacionándolas con sus inquietudes personales, el estado de los estudios cervantinos en su tiempo y las visiones románticas o positivistas de Cervantes y, en especial, del Quijote.

\section{DEL CERVANTISMO ROMÁNTICO AL POSITIVISTA}

Las numerosas referencias decimonónicas a Cervantes, en el marco del desarrollo del estudio filológico e histórico de la literatura, tienden a perfeccionar la erudición cervantina y a transcenderla con diversas interpretaciones ${ }^{8}$. Como era de esperar, el romanticismo potenció las lecturas idealistas del Quijote. Ya Heine, al que Bartrina tradujo e imitó, proyectó en esta novela el contraste de la candidez y la ironía heinianas (Balzer 2004-2006) y Schelling consolidó la tendencia a interpretar el Quijote como una antítesis entre ideal y realidad.

El positivismo, entroncando con las lecturas empiristas e ilustradas, a la vez que potenció el estudio con voluntad científica, arremetió contra la búsqueda de sentidos ocultos, que había promovido sobre todo Nicolás Díaz de Benjumea (Martínez 2001). De todos modos, no se erradicó la dicotomía romántica ideal/real, sino que, a menudo, se reformuló o reinterpretó. Ya en 1837, Émile Littré (1875: 176-192) caracterizó a don Quijote mediante la dialéctica «hallucination»/«raison».

Juan Valera (2007: 51-52; González 2006), que intentó conciliar el idealismo con cierto positivismo, en el discurso leído el 25 de septiembre de 1864 en la Real Academia Española, advertía:

Yo no entiendo ni acepto muy a la letra la suposición de que don Quijote simboliza lo ideal y Sancho lo real. Era Cervantes demasiado poeta para hacer de sus héroes figuras simbólicas o pálidas alegorías9.

Similarmente, el positivista y darwinista Tubino (1872: 193, 202 y 205) consideraba el Quijote fruto del «arte de concertar», «las tendencias antagó-

8. Véanse los panoramas de Rius (1904, III); Icaza (1918: 127-128); Finello 1987; Montero (1997 y 2005: 55-56); Alonso 2005; Armero 2005; Close 2005; F. Valera 2007; Cuevas (2015 y 2016).

9. J. Valera (1961: 942 y 1243-1244) se mostró crítico con Bartrina. 
nicas de la vida», «en un sabio equilibrio equidistante de toda exageración», aunque confiaba en la derrota del idealismo:

[Cervantes] sabe que el sentimiento es en los hombres más poderoso que la razón: halla entre la forma artística y la sensibilidad lazos misteriosos, secretas correspondencias. Su libro, pues, antes que disertación escolástica, será una agradable novela, un cuadro realista, un animado teatro donde comparezcan los principios que combate y las esperanzas que sirve, donde batallen lo pasado y lo porvenir, el caballero y la burguesía, el idealismo y la realidad, hasta que el primero resulte convencido de error y la segunda victoriosa sin ulterior recurso ${ }^{10}$.

En cambio, Manuel de la Revilla (2006: 184-185; García 1981: 151-153), que había evolucionado del krausismo al positivismo, negó la identificación de los protagonistas del Quijote con las dos grandes tendencias filosóficas decimonónicas:

\begin{abstract}
Ni Sancho es el positivismo ni el idealismo D. Quijote. Sancho es simplemente el buen sentido vulgar, sin idea ni elevación de ningún género, acompañado del cálculo egoísta y utilitario; y D. Quijote, el idealismo falso, imposible y anacrónico que se identifica con la locura. La realidad dista del uno como del otro, y ambos se estrellan al tocarla, resultando por ende tan censurable y ridículo Sancho como D. Quijote y sin resolver la oposición entre ambos. No es, pues, la oposición entre lo ideal y lo real lo que aparece en el Quijote, sino la vanidad, ridiculez e impotencia del falso idealismo y del positivismo grosero e incompleto. La necesidad de aunar lo ideal con lo real, de reducir el primero a sus límites razonables y posibles y encarnar en lo segundo lo que hay de necesario y legítimo en la idea, es lo que resulta de la obra ${ }^{11}$.
\end{abstract}

\title{
3. UNA VELADA CERVANTINA
}

Bartrina fue uno de los principales promotores de las veladas literarias y musicales del Centre de Lectura, ateneo progresista de su ciudad natal ${ }^{12}$. La primera cervantina conocida se celebró el 23 de abril de 1872 (Vall 2005: 157;

10. Tubino (2003 y 2005 [1880]: passim) se refiere elogiosamente a Bartrina en su Historia del Renacimiento literario contemporáneo en Cataluña, Baleares y Valencia.

11. Sotelo Vázquez (2014: 24-28) se ha ocupado ya de la relación de Revilla y Bartrina. No puedo entrar en la actitud de otros allegados a este hacia Cervantes, como Valentí Almirall, Antoni de Bofarull, Pompeu Gener, Joan Giné i Partagàs, Apel·les Mestres, Alfred Opisso, Josep Lluís Pellicer y Salvador Sanpere i Miquel. No abordaré tampoco la presencia del Quijote en los escritores realistas, que vieron en Cervantes un precedente.

12. En su biblioteca, se encuentra documentación de la entidad con referencias a Bartrina, de las que solamente citaré algunas, y publicaciones donadas por él, algunas de las cuales he podido localizar mediante el libro de registro. En la prensa, abundan también las noticias sobre la participación de Bartrina en esta sociedad. Omito la bibliografía sobre la misma y sobre sus socios. 
Ferré 2007: 77 y 2013: 34), al creerse, como era tradicional, que Cervantes murió en el mismo día de 1616, aunque lo hizo el anterior ${ }^{13}$. Por cierto, en el «arabesco» XXII de la segunda edición de Algo, Bartrina (1877: 156) ironiza:

De un escritor, de un artista de genio, podemos siempre, para deplorarlo tristes, saber el día en que muere y nunca el día en que nace, para celebrarlo alegres ${ }^{14}$.

El Diario de Reus y La Redención del Pueblo calificaron la concurrencia de «escogida», bien fuera en grado positivo o superlativo, y el segundo, además, de «numerosa», y ponderaron los aplausos de todas las intervenciones y la satisfacción del público. El primer periódico describió la decoración del local:

Estaba adornado como esta clase de funciones requieren, destacando en fondo negro y bajo dosel, el busto del eminente escritor ciñendo la diadema del genio: la corona de laurel. Al pie del pedestal, estaban colocadas dos ediciones del Ingenioso hidalgo D. Quijote: la una, de gran tamaño y con láminas abiertas al acero; la otra, facsímile de la primera edición publicada en España por el mismo autor ${ }^{15}$.

13. Erróneamente, El Tarraconense. 114, 24.IV.1872, p. 2, se refirió a la sesión como si hubiera de tener lugar este día. Se había anunciado ya en el Diario de Reus. 95, 12.III.1872, p. 1; la corroboró El Eco del Centro de Lectura. 7, 10.IV.1872, p. 8, y el 19 de abril la aprobó la Junta de Gobierno (Actas, 2). Dan noticia de la celebración el Diario de Reus. 95, 25.IV.1872, p. 1; La Redención del Pueblo. 95, 25.IV.1872, p. 3, y El Eco del Centro de Lectura. 8, 25.IV.1872, pp. 1-15, que reproduce las crónicas de dichos periódicos, algunas de las intervenciones y el autorretrato de Cervantes del prólogo de las Novelas ejemplares.

14. Se publicó también en forma de pensamiento, en catalán (Bartrina 1874b) y en castellano (Bartrina 1881: 280).

15. El segundo ejemplar mencionado debe corresponder a la edición de Francesc López Fabra, a la que acordó suscribir el Centre de Lectura su Junta de Gobierno el 15.X.1871 (Actas, 2). Esta entidad consta entre los suscriptores en el Boletín de la Reproducción Foto-Tipográfica de la $1^{a}$ edición de Don Quijote de la Mancha. 7, 1872, p. 4; 8, 1873, p. [4], y 10, 1880, p. [7] (Bacardí y Estany 2006: 31). El otro ejemplar, dado el tamaño y que lo ilustran láminas grabadas en acero, debe ser de la edición publicada en Barcelona por Tomás Gorchs en 1859, reimpresa por la misma editorial en 1863 y reeditada por Espasa Hermanos. El 21 de abril de 1864 la Junta de Gobierno aprobó la suscripción a una edición de «D. Quitjote de la Mancha» que se alude como «monumental» (Actas, 1), adjetivo que se suele aplicar a esta. En la Biblioteca del Centre de Lectura, existen otras, entre las cuales la de López Fabra y la de Gorchs de 1859, pero esta figura como donada por una asociación creada en 1929. De todos modos, ya el 4 de enero de 1874 se detectó la desaparición de ejemplares (Actas de las juntas generales). En 1917, poco después de morir Francesc Bartrina, Magdalena, la hermana pequeña, hizo donación de diversos libros o revistas de la familia, de muy variadas materias, a la Biblioteca de Catalunya (prensa de la época; Fontanals y Losantos 2007: 110). La consulta del libro de registro me ha permitido localizar la mayoría. Entre ellos, se encuentra un ejemplar de la edición barcelonesa del Quijote publicada en 1869 por la Librería de Lance de Ramón Pujal, con notas, entre otros, de Juan Antonio Pellicer y Diego Clemencín (sig. Cerv. 32-VI-26, reg. 41165). Mientras que en otros libros de Bartrina se hallan diversas anotaciones e incluso esbozos de 
Inauguró la velada el discurso presidencial del médico positivista y darwinista Tomàs Lletget i Cailà, uno de los mentores de Bartrina (Vall 2005: 125 126 y 2012a: 110 ${ }^{16}$. Justificó el homenaje, «a imitación de otras muchas Sociedades de la Península Ibérica», porque el Centre de Lectura es «admirador entusiasta» de las «eminencias artísticas y literarias». En particular, lamentó los infortunios de Cervantes, aunque a «seres privilegiados» como él «los obstáculos les sirven tan solo para estimular su actividad», y «la ingratitud y aun el desdén de sus coetáneos», que comparó al sufrido por Sócrates, Galileo, Colón y Newton.

Luego, José Rofes Aleu leyó un soneto suyo «A Miguel de Cervantes Saavedra», en que lo elogió, tópicamente, como «genio creador con la figura humana»y, «de la natura, intérprete divino» ${ }^{17}$. Las antiguas reyertas satíricas entre el monárquico Rofes y el republicano Bartrina, evocadas por Eduard Toda (1920: 345-346) y plasmadas en la prensa local, no impidieron que colaborasen en diversas actividades. En cambio, el jocoso romance, «A un tal Cervantes», que declamó a continuación Bartrina, era de un gran amigo suyo, Gerardo Blanco, con el que había adaptado La traviata, de Verdi (Vall 2005: $150)^{18}$. Ambos diarios indican que fue remitido por el autor y La Redención del Pueblo precisa que lo hizo desde Barcelona, a pesar de que residió temporalmente en Reus (Gras 1911: 18). Recobrándose la gravedad, un antiguo compañero de colegio y contertulio de Bartrina (Gras i Elías 1909: 98-99 y 1911: 8 y 12; Martí 1920: 316 y 319; Centro de Lectura 1900), Lluís Quer, leyó un soneto suyo titulado «El 23 de abril de 1616», centrado, por tanto, en el «duelo» por la muerte de Cervantes ${ }^{19}$.

Tras un descanso, Rofes, como había hecho Lletget, resaltó el desinterés por Cervantes en su tiempo, que contrastó con el «culto idolátrico» posterior, el cual se explicaría porque el Quijote, «bajo las formas más delicadas y suaves, entraña el germen de las revoluciones futuras», y comparó a su autor, «alcabalero corriendo de Seca en Meca», a Camõens muriendo pobre, Napoleón en Santa Elena («cual otro Prometo»), Colón encadenado por Bobadilla y Homero y Milton ciegos ${ }^{20}$. En la versión escrita, no figura la equiparación a Espronceda, que, según el Diario de Reus, culminó su alocución.

Desgraciadamente, no se publicó la de Bartrina, pero al menos la resume este periódico:

El Sr. Bartrina, con la facilidad que le es propia, siguió en el uso de la palabra, ocupándose de la vida íntima de Cervantes desde 1605 a 1614, describiendo el estado de la literatura en Europa en aquella época y dando

obras suyas, que han sido ignorados por los estudios sobre él, en este solamente se ha marcado algún pasaje.

16. El Eco del Centro de Lectura. 8, 25.IV.1872, pp. 2-5.

17. Ibid., p. 1.

18. Ibid., p. 5.

19. Ibid., p. 5.

20. Ibid., p. 7-8 
a conocer, acerca del Quijote del falso Avellaneda, datos de suma importancia. Inútil es decir que concluyó entre aplausos de la concurrencia ${ }^{21}$.

El año anterior, El Eco del Centro de Lectura había editado, tras la poesía de Bartrina «Indigestión», un artículo anónimo, que podría ser suyo, si bien no necesariamente, sobre la devoción de Calderón por Cervantes:

Grande debió de ser la admiración que la lectura del Quijote produjo en el espíritu del eminente Calderón, cuando este en multitud de comedias la dejó consignada [como se ilustra en el artículo] para confusión de los que, envidiosos de la gloria de Cervantes, pretendían apoyarse en los autores dramáticos para herir a mansalva la reputación del inmortal esclavo de Argel, que, en su Quijote, había atacado los defectos generales de los dramas de su época ${ }^{22}$.

Cerró la sesión la lectura por Quer de la poesía «A Cervantes», de Ventura de la Vega, autor de diversos poemas y dramas cervantinos.

Al año siguiente se anunció una nueva velada cervantina en el Centre de Lectura $^{23}$. Sin embargo, lamentablemente, no se realizó «por no poder contar

21. Los límites cronológicos deben obedecer a las fechas de publicación de la primera parte del Quijote y de la continuación apócrifa. En El Ateneo Tarraconense de la Clase Obrera en homenaje de admiración y respeto al inmortal Miguel de Cervantes Saavedra al conmemorar el aniversario del fallecimiento del egregio autor del ingenioso hidalgo Don Quijote de la Mancha. Tarragona: Tipografía de F. Arís e Hijo, 1872, p. 4, se encuentra un capítulo firmado «J. M. B.», como acostumbraba Bartrina, sobre la «reparación» que debe a Cervantes Tarragona por ser la ciudad donde figura publicado el Quijote de «Avellaneda». No obstante, a pesar de que en él se especula sobre este pseudónimo, no concuerda plenamente con el resumen del discurso de Bartrina ni hay otros indicios suficientes para atribuírselo con seguridad, a pesar de que ayudaría a explicar por qué no publicó su alocución en El Eco del Centro de Lectura. El capítulo se ha adjudicado, sin indicar los motivos, a «J. M. Barberà», aunque una errata ha llevado a confundirlo con Jaume Barrera (Bacardí y Estany 2006: 36-37 y 241). Supongo que el primero debe identificarse con el clérigo y escritor reusense Josep Maria de Barberà i Canturri, que entonces era director del instituto de segunda enseñanza de Tarragona (expediente suyo del Arxiu Històric de la Universitat de Barcelona y El Tarraconense. 21, 21.I.1872, p. 2) y que participó en el Ateneo Tarraconense y, en concreto, en sus celebraciones cervantistas, como muestra la revista de esta entidad. El Tarraconense. 115, 25.IV.1872, p. 2, revela solamente que los autores del libro de homenaje, que «han ocultado sus nombres modestamente bajo iniciales», son «personas conocidas de círculos literario de esta capital» y «el público los averiguó pronto». De todos modos, he detectado que el capítulo de Alfredo Opisso (1872), publicado también en La Ilustración (Opisso 1881), lleva la firma «S.», aunque el hecho de doblar esta consonante caracteriza su apellido. Lo plagió su amigo Pompeu Gener en un artículo fechado en Barcelona en mayo de 1877 (1878; se conserva un manuscrito y compaginadas, ambos con correcciones, en su fondo personal del Arxiu Històric de la Ciutat de Barcelona, cajas 6 y 4, respectivamente). Gener se ocupó de Cervantes en otros escritos, algunos olvidados. Entre estos, reseñó en Tribuna. 4380, 21.X.1912, p. 1-2, la edición de las Novelas ejemplares por Thomas Nelson and Son. El autor de la introducción, el canario R[afael]. Mesa López, le sugirió, en una carta sin fecha, pero que tiene que ser del mismo año, que prologase el Quijote para dicha editorial (fondo de Gener citado, caja 10), pero no lo hizo.

22. El Eco del Centro de Lectura. 55, 30.VII.1871, p. 3. Entre los libros donados por Magdalena Bartrina a la Biblioteca de Catalunya, se encuentra un ejemplar, que no he localizado, de la parte VI de los Autos sacramentales de Calderón (reg. 41196). Existen diversos estudios sobre la presencia cervantina en el teatro calderoniano.

23. La Redención del Pueblo. 79, 4.IV.1873, p. 3. 
con medios suficientes» ${ }^{24}$. Con todo, el 23 de abril se llevo a cabo un homenaje a Cervantes en el Teatro Principal de Reus, en que se leyeron poemas en su honor y se coronó un busto suyo ${ }^{25}$. El Centre de Lectura celebró otra velada cervantina, el 23 de abril de 1880, año en que, el 4 de agosto, murió Bartrina $^{26}$.

\section{4. «Biblografía CERVÁntica: D. QUiJOTE EN EL TEATRO»}

Como se indica en el «número prospecto» de la revista madrileña Cervan$t e s^{27}$, su objetivo inicial era promover la suscripción para un monumento a este escritor en Alcalá de Henares, que se inauguraría el 9 de octubre de 1879. El primer número se abrió con sendas cartas, fechadas el 23 de abril y el 14 de junio de 1875, de José María Casenave, su director, a su «buen amigo» Carlos Frontaura, pidiéndole y agradeciéndole, respectivamente, la adhesión a esta campaña de El Cascabel, periódico que dirigía ${ }^{28}$.

A partir del n. ${ }^{\circ} 19$ de Cervantes (8.I.1876), figuran Casenave, como fundador, y, como director, M[anuel]. Tello Amondareyn, que era redactor de la revista desde los inicios, y ambos como propietarios. Después del n. ${ }^{\circ} 42$ (30. VI.1876), pasó a publicarse en Barcelona, iniciando una segunda época y una nueva numeración. En el primer número de esta etapa (15.X.1876), se explicó que el director había estado ausente de Madrid los tres últimos meses y que, residiendo en la Ciudad Condal, había reorganizado la redacción y la administración. La revista, generalmente semanal, se convirtió en bimestral, pero pasó de tener 18 páginas a 32, pensando en su encuadernación como libro, y aspiraba a una mayor proyección hispanoamericana.

En el quinto número de la nueva etapa (15.XII.1876), que parece ser el último de la revista, se editó el artículo de Bartrina (1876), en forma de carta dirigida a Leopoldo Rius, fechada en Barcelona el 2 de diciembre de este año ${ }^{29}$. Bartrina (ibid.: 157), tras atribuir a «una afortunada casualidad» que la

24. Actas, 2, 20.IV.1873.

25. La Redención del Pueblo. 94, 23.IV.1873, p. 3; Diario de Reus. 95, 22.IV.1873, p. 2; 96, 23.IV.1873, p. 4; 98, 25.IV.1873, p. 3.

26. El Eco del Centro de Lectura. 18, 2.V.1880, pp. 1-8.

27. A partir del n. ${ }^{\circ}$ 8, 30.VIII.1875, al subtítulo «Revista Literaria», se añadió «Eco de los Cervantistas Españoles» y, desde el n. ${ }^{\circ}$ 19, 8.I.1876, la palabra «Eco» fue sustituida por «Órgano».

28. Justamente la ignorada fuente de la traducción juvenil de Bartrina «Esperanses!» (Vall 2003: 1156 y 2005: 139; Cabré 2012: 93) es un poema de Carlos Frontaura publicado en El Correo de la Moda. 170, 16.VII.1856, pp. 218-219.

29. En Memoria de Madrid, solamente se han digitalizado las pp. 158-160. Accesible en: <http:// www.memoriademadrid.es/buscador.php?accion=VerFicha\&id=146735\&num_id=6\&num_total=47>. Aunque en Cervantes se habían editado diversos poemas de Josep Martí i Folguera, no tuvo que actuar necesariamente como mediador, dado que Bartrina tenía ya múltiples relaciones y suficiente fama. Por otra parte, en el primer número barcelonés, p. 4, se había manifestado la voluntad de estrechar los lazos con los escritores catalanes. Leopoldo Rius (1895-1904: II, 361) no aclara si Bartrina le envió la carta directamente o lo hizo mediante la revista. 
publicación llegara a sus manos, explicó que había sacado las «noticias» que aportaba de «unos apuntamientos» empezados «hace algún tiempo» con el propósito de «estudiar los viajes póstumos de don Quijote, a quien la fama negó la tranquilidad de la tumba y que, aún hoy, anda recorriendo el mundo con universal contentamiento».

A su vez, Rius (1876), en una misiva fechada en Barcelona el 1 de julio de $1875^{30}$, había completado, con una «Lista de algunos dramas, comedias, sainetes y pasos con argumentos sacados de las obras de Cervantes», un inventario de José María Asensio (1874: 29-33): «Algunas piezas de teatro cuyos argumentos están tomados de las obras y de la vida de Miguel de Cervantes». Evidentemente, la conjunción debiera ser disyuntiva. Por lo tanto, el campo de las aportaciones fue restringido por Rius a las obras cervantinas y por Bartrina al Quijote.

Bartrina (1876: 157 y 159) debía desconocer el contenido de la bibliografía de Asensio, porque supone, en lugar de afirmarlo, que «la lista» conjunta «debe ser ya numerosa» y reitera obras mencionadas por este, si bien aportando más datos: Les folies de Cardenio, de Pichou; D. Quichotte de la Manche, de Guérin de Bouscal ${ }^{31}$; Sancho Pança gouverneur, de Dancourt; Le curieux impertinent, de Du Brosse; Sancho Pança, de Du Fresney; D. Quichotte, de Sardou, y D. Chisciotte alle nozze di Gamaccio, que Asensio cita por el libretista, Stefano Ferrero, y Bartrina alude por el músico, Saverio Mercadante. Por otra parte, Bartrina omite obras aducidas por Asensio relativas al Quijote: Sancho Pança, de Destouches, y el ballet comique Don Quichotte, de Charles-Antoine Coypel, aunque Asensio lo consideró anónimo.

Bartrina clasifica sus aportaciones por países: Francia, Inglaterra, Italia y Alemania. Gras i Elias (1909: 100) evoca que Bartrina impartió algún curso de francés en el Centre de Lectura, a pesar de que, por lo que recuerda Toda (1920: 347), solamente cursó las clases iniciales de este idioma de dicha entidad, como hizo con las de inglés ${ }^{32}$. Además, en el curso 1864-65, se había matriculado en las Escuelas Pías de Reus de una asignatura opcional de lengua francesa ${ }^{33}$. El propio Bartrina, en una carta a Josep Martí i Folguera fechada en Barcelona el 15 de junio, que debe ser de 1876 (Ferré 2007: 77 y 2013: 36), explica que empezaba «a saber el inglés para traducirlo» y que confiaba en que, cuando lo dominase, emprendería el aprendizaje del alemán, que, animado por un amigo, creía que lo entendería al cabo de un año de estudiar-

30. Editada en la 4, 9.IX.1875, pp. 129-131, remitida el 10 de octubre del año siguiente a Tello y reeditada en Cervantes. 3, 15.XI.1876, pp. 81-84. Sobre la primera publicación periódica, véase Cuevas 2011.

31. Fue citada también por Rius (1876: 83), pero escribiendo mal el apellido, «Booscal», y posponiendo un año su estreno, por influencia de su confesada fuente: Siete cartas sobre Cervantes y el Quixote, dirigidas al muy honorable Doctor E. W. Thebussem, barón de Tirmenth. SS. TT. en los años de 1862 a 1868 por el señor M. Droap [Mariano Pardo de Figueroa]. Cádiz: Impr. de la Revista Médica, 1868 , p. 13.

32. Entre los libros donados por Joaquín M. Bartrina al Centre de Lectura o por su hermana a la Biblioteca de Catalunya, se encuentran algunos sobre distintas lenguas.

33. Documentación guardada en el instituto de secundaria Gaudí, de Reus. 
lo $^{34}$. Según evoca Martí i Folguera (1883: 2), Bartrina aprendió inglés para traducir a Darwin, a pesar de valerse de una versión francesa (Zabalbeascoa 1968a y 1968b: 273; Gomis y Josa 2009). Rossend Arús (1880: 6) evoca que Bartrina había aprendido por su cuenta, además de la lengua inglesa, la italiana.

Por lo tanto, podría haber leído algunas obras en la lengua original. Bartrina (1876: 157-158) explicita que había «tenido el gusto de leer» Les folies de Cardenio en una antología de Édouard Fournier, Le théâtre Français au XVI et au XVII siècle (París: Laplace, Sánchez et C ${ }^{\text {ie }}, 1871$ ), e indica que Le libraire du Pont-Neuf se encuentra en otra compilación teatral: Les contemporains de Molière. I (París: Firmin Didot, 1866). Prueba de que no se guiaba meramente por el título de las obras, Bartrina (ibid.: 158) advierte que Don Quichotte, de Prosper Mérimée, «no tiene absolutamente nada que ver con la creación de Cervantes». De todos modos, la aclaración es hiperbólica, porque, en la obra, se compara al protagonista, el viejo coronel Saqueville, con don Quijote.

En cualquier caso, Bartrina (ibid.: 157-159) cita diversas fuentes secundarias:

1. Manuel du libraire et de l'amateur de livres, de Jacques-Charles Brunet, a raíz de Les folies de Cardenio, de Pichou. De todos modos, quizás lo utilizó también para otras obras.

2. Histoire des marionnettes, de Charles Magnin, a propósito de Don Quichotte, polichinelle, de Valois d'Orville ${ }^{35}$.

3. Biographie universelle des musiciens et bibliographie générale de la musique, de François-Joseph Fétis, con relación a Don Quijote, de Anton Hubatschek, y Sancho Panza dans son isle, de André Danican Philidor, «el célebre jugador de ajedrez» ${ }^{36}$. Parece que esta enciclopedia le proporcionó otros datos.

4. «Mr. F. Clay's 'Don Quixote'». The Athenceeum. 2553, 30.IX.1876, pp. 441-442, artículo del que saca todas las informaciones sobre literatura inglesa. En él, se menciona también Die Hochzeit des Camacho, de Mendelssohn, que Bartrina (1876: 160) cita en el apartado dedicado a Alemania.

Se reprodujo un «extracto» del texto de Bartrina, con escasas supresiones y ponderando su carácter «curioso» y «muy erudito», en La Academia, entre

34. En las cartas de Bartrina a Joaquim Botet i Sisó del ms. 1880, f. 5-8, de la Biblioteca de Catalunya, sin fecha, pero con referencias a un libro y un artículo de 1876 , le indica que encarga a un conocido la traducción de un texto en alemán (Zabalbeascoa 1968b: 29, 453-455 y 461).

35. Entre los libros donados a la Biblioteca de Catalunya por Magdalena Bartrina, se encuentra una edición de la Histoire des marionnettes publicada en París por Michel Lévy Frères en 1862 (sig. A 80-8-456, reg. 41179). La referencia citada se encuentra en la p. 167. Parece que se hubiera forzado el libro para que quedara abierto por ella para copiarla.

36. Bartrina debía ser, pues, aficionado a este juego y, seguramente, conocer la defensa que lleva el nombre de dicho ajedrecista. 
otras noticias agrupadas con el título «Cervantina» ${ }^{37}$. Sin embargo, «D. Quijote en el teatro» no se ha compilado en ediciones de obras de Bartrina, por su carácter bibliográfico o inconscientemente, ni me consta que haya sido tenido en cuenta por los estudios sobre él.

Sin embargo, se trata de una contribución considerable, incluso en comparación con otras más recientes sobre la presencia del Quijote en el teatro (Givanel 1915; Pérez 1947), en la música o sobre su recepción en distintos países (la bibliografía es muy abundante), aunque se la recuerda escasamente (Rius 1895-1904; Givanel 1915 y 1916-1925; Pérez 1947; Sedó 1947; Herreras 1980; Cuevas 2015; Garrido Ardila 2014, confesando que no la ha podido consultar).

\section{5. «NOTAS A ALGUNAS NOTAS DEL QUIJOTE»}

Josep Roca i Roca (1916: 11, 26 y 31), cuya gran amistad con Bartrina se remonta a antes de la Revolución de 1868 y que le publicó diversos escritos (Vall 2002: 115, 2003: 1159 y 1177, 2005: 163-164; Colom 2012: passim), guardaba, como una reliquia, manuscritos de su amigo en un cajón de su escritorio. Felizmente, transcribió una larga lista de proyectos escrita por el propio Bartrina, que incluyen unas «Notas a algunas notas del Quijote» ${ }^{38}$. Aunque abundan las glosas de la novela y hemos visto que la familia Bartrina poseía una edición de 1869 con anotaciones, entre otros, de Pellicer y Clemencín, es probable que el título se refiriera a las 1633 notas puestas por el Exmo. e Ilmo. Sr. D. Juan Eugenio Hartzenbusch a la primera edición de El ingenioso hidalgo reproducida por D. Francisco López Fabra (Hartzenbusch 1874), especialmente por su novedad, su ambición y la notoriedad de su publicación autónoma.

37. I, 11.III.1877, pp. 156-158. Dirigía esta publicación el mencionado Tubino. Se plagia la versión de La Academia, como prueba la reproducción de errores que no figuraban en la de Cervantes, en un artículo firmado por «X. V.» y sin ninguna referencia a Bartrina, «Don Quijote de la Mancha», de La Revista Blanca. 165, 1.V.1905, pp. 669-670.

38. Algunos ejemplares donados por Magdalena Bartrina a la Biblioteca de Catalunya tienen relación con estos u otros planes suyos. Según tuvo la amabilidad de informarme Anna Gudayol, en el fondo personal de Roca de dicha biblioteca (Escobedo 1981), no se encuentran documentos de Bartrina. Roca (1880: 2) recuerda que los proyectos de su amigo corrían de mano en mano. Él mismo, con su conocido pseudónimo «P. K.», recreó una idea de Bartrina en La Campana de Gràcia. 742, 26.VIII.1883, p. 1. También Roca tuvo relación con círculos cervantinos y escribió sobre el Quijote (Riera 2002: 52-53 y 79; 2005: passim; Bacardí y Estany 2006: 85; Colom 2012: 220 y 703 ). 


\section{TEMAS CERVANTINOS EN LA OBRA LITERARIA DE BARTRINA}

Bartrina (1874a: 14-16 y 1877: 27-30) alude a Cervantes en la octava estrofa de «Epístola», dirigida a «Fabio» (como la de Andrés Fernández de Andrada, entre otras):

Eso es cierto, pero tú no te metas en dibuni en saber vidas aje-, como dijo el otro, y ve de enviarlos a Belcebú 39 .

Como ya se ha advertido (Mario 1992: 196 y 2006; Rovira 2002), en esta estrofa se recrean los versos de cabo roto de Urganda la Desconocida «Al libro de don Quijote de la Mancha»:

No te metas en dibúni en saber vidas ajéque en lo que no va ni viepasar de largo es cordú(Cervantes 2015: 24, v. 50-54) $)^{40}$.

Entre los «arabescos» de las Obras en prosa y verso (Bartrina 1881: 328), figura uno en que se prueba el común desprecio por el ideal con la mofa del ingenioso hidalgo:

Es muy justo se nos note que de lo ideal nos burlamos: la gran prueba es que encontramos ridículo a D. Quijote.

39. El poema puede corresponder a la obra «humorística» de este género que Bartrina leyó en las veladas del Centre de Lectura del 10 de septiembre de 1870 (Diario de Reus. 216, 8.IX.1870, p. 2) y del 10 de marzo de 1872 (El Eco del Centro de Lectura. 6, 25.III.1872, pp. 5-7; Diario de Reus. 95, 12.III.1872, p. 1; La Redención del Pueblo. 58, 12.II.1872, p. 3; Zabalbeascoa 1968b: 123-124 y 168). Se editó una traducción catalana del mismo por «C. Gumà», conocido pseudónimo de Juli Francesc Guibernau, en La Esquella de la Torratxa. 2, 26.I.1879, p. 2, y L'Aureneta. 39, 25.I.1880, pp. 516-518. Guibernau, que se interesó también por el Quijote (Riera 2002: 44-45 y 2005: passim), tradujo otros poemas de Bartrina y, entre otros escritos en que lo imita o elogia, en el artículo «Un record». La Campana de Gràcia. 635, 7.VIII.1881, p. 2, firmado con otro conocido pseudónimo suyo, «Fantàstic», recrea un cuento que le explicó Bartrina, después de ponderar que la «intel·ligència» de este lo abarcaba «tot»: «excursions històriques, investigacions científiques, sutileses filològiques, profundíssimes concepcions filosòfiques, ramellets humorístics».

40. «Urganda la Desconocida» se usa como pseudónimo — seguramente por influencia del Quijote, aunque el personaje se remonta al Amadís de Gaula - en un poema caricaturesco, «Museo biográfico», publicado en una revista humorística reusense en que participó Bartrina: El Sorbete. 2, 2.VIII.1868, pp. 2-3. 
Sin embargo, lo matizan un par de aforismos. En el primero, Bartrina (1881: 279) compara la servidumbre del raciocinio a la fantasía con la de Sancho Panza: «Mi razón se deja extraviar por mi imaginación y la sigue como un fiel escudero seguiría a su dueño, como Sancho a D. Quijote». La lucha entre «razón» e «imaginación», al igual que la de esta primera facultad con el sentimiento (Mainer 1998), se reitera en la obra de Bartrina, manifestando el conflicto entre sus aspiraciones idealistas, exaltadas en sus orígenes románticos, y el desengaño, corroborado por el positivismo.

En el otro pensamiento, Bartrina (1881: 281), jugando con la aritmética, encarna en estos personajes la dualidad humana: «Quijote y Sancho son dos hombres; son dos mitades de un hombre; son un hombre; son el hombre». Esta síntesis se podría explicar en términos darwinistas, a partir de otros textos de Bartrina (Vall 2012a: 130-135), por las reminiscencias atávicas.

En «Un pequeño comentario al Quijote», Federico Rahola (1882) desarrolla este pensamiento, como hizo también con una narración de su amigo Bartrina (Vall 2005: 157), al que elogió en diversos escritos (Vall 2003: 1170). Rizando el rizo, dobla la duplicidad sumando a los personajes sus monturas, que reflejan sus «cualidades», «no siendo en realidad cuatro, sino dos, o como decía Bartrina, uno tan solo» (Rahola 1882: 235). Don Quijote es «un loco razonador que tiene muchos intervalos lúcidos» y Sancho «un cuerdo simple que muestra varios paréntesis de locura», de modo que «se contemplan del mismo modo que la cuña y la mesa que cojea» (ibid.: 234).

Fernando Noriega Olea encabezará con el último pensamiento de Bartrina citado un artículo sobre «Los escolares españoles en el Centenario del Quijote», porque, «entre tantos estudios (admirables algunos de ellos, como acontece con los Heine, Turguénev y Fitzmaurice-Kelly), destácase la frase de Bartrina, por ser la que de modo más preciso y concreto sintetiza la significación del Quijote» ${ }^{41}$.

\section{7. «DON SANCHO PANZA», NARRACIÓN DESARROLLADA POR JOSEP Miró I FolguerA}

Entre otros proyectos bartrinianos terminados por amigos suyos, se encuentra este relato (Bartrina y Miró 1885). Adolfo Pons i Umbert (1892: 300) indicó que «algunos de los pensamientos últimos del gran escéptico» habían sido publicados por Martí i Folguera en La Ilustración Ibérica. Ello favoreció que localizara la narración en esta revista barcelonesa (Vall 2002: 116), de lo que di noticia a Carola Duran para que la incluyera en su comunicación sobre las ideas de Bartrina recogidas por sus amigos (2002), en que mantuvo esta atribución. 
Sin embargo, la firma se reduce a «J. M. Folguera» y el signatario aclara que, a diferencia de Josep Martí i Folguera, no trabó amistad con Bartrina hasta «las postrimerías de 1879 », convaleciente este de tisis en la casa de la

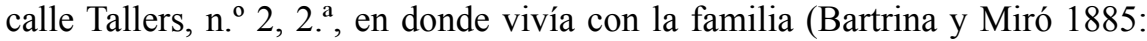
795). Por otra parte, la mentalidad y el estilo son muy distintos. Se podría pensar en Josep Miró i Folguera, por la fecha de la amistad, la afinidad ideológica y cuestiones formales, además de sugerirlo la considerable dedicación de este escritor entonces a la narrativa y el aumento de sus colaboraciones en dicha revista. De todos modos, lo prueba directamente la inclusión de este texto en su libro El ratoncito (Miró [1893]), de donde se reprodujo el 14 de abril de 1893 en La Vanguardia. 3568, pp. 1-242. La edito en un apéndice del presente artículo a partir del libro y anotando las variantes de La Ilustración Ibérica.

Miró i Folguera había homenajeado a Bartrina en una necrología (1880), que coincide con la nota preliminar de la narración en resaltar que «la naturaleza formó un cuerpo débil enfermizo para albergar la intensidad de aquella fuerza intelectual inacabable y activa como pocas», en la cita «iQué dulce es la concepción (exclamaba él mismo), pero qué penoso es el parto!»y en ponderar la multidisciplinariedad de Bartrina:

Hoy dejaba la botánica para estudiar la física, mañana se dedicaba a la antropología para ver después la historia; para él, no había estudio alguno que no reportase buenos frutos. Su clarísima inteligencia encontraba relaciones misteriosas entre las ciencias más alejadas al parecer.

Miró i Folguera (1878) había consagrado un artículo al escepticismo en que, con concepciones similares a Bartrina, pero formuladas evidenciando más el componente comtiano, explicaba esta «gran plaga del espíritu que parece encarnada con la juventud de nuestro siglo» como un «período de transición entre el estado del creyente y el estado del científico», por lo que la solución sería «inculcar en el ánimo de nuestros hijos las semillas imperecederas de la ciencia». El escepticismo de Bartrina es bien conocido (Vall 2003). Miró i Folguera confiesa el suyo en una carta a Pompeu Gener del 29 de mayo de $1881^{43}$. En la presentación de la narración (Miró [1893]), atribuye el pesimismo al contraste entre los «ideales abstractos y engañosos de justicia y de virtud»y la «organización natural», detectado por la dolorosa «conciencia», y destaca como referentes del mismo a Leopardi, Schopenhauer y Hartmann ${ }^{44}$. Josep Pla (1969: 559-601), a quien Josep Miró i Folguera

42. Alguna reseña del libro destacó esta narración.

43. Fondo de este último guardado en el Arxiu Històric de la Ciutat de Barcelona, caja 10.

44. Rossend Arqués (1986) se ha ocupado ya del leopardismo de Bartrina. Entre los libros donados por Magdalena Bartrina a la Biblioteca de Catalunya, se encuentran Le poesie, de Leopardi, Livorno: F. Vigo, 1869, edición aumentada y revisada de Giuseppe Chiarini (sig. A 83-8-8925, reg. 41316) y La philosophie de Schopenhauer, de Théodule Ribot, París: Germer Baillière, 1874 (sig. A 1-8-1240, reg. 41326). Se había comparado ya a Bartrina con este filósofo (Gener 1882: 535; dos 
acogió en sus inicios periodísticos, lo recuerda como «un home molt intel-ligent» y refiere que usaba un adjetivo que atribuía a Bartrina: «sinequanònic» (derivado de sine quanon).

Centrándonos en la narración, su altruista protagonista, José de Quijana y Salazar, apodado «Quijote» (contribuyendo a ello su apellido, el descender de una familia manchega aristocrática venida a menos y su talante), se convierte en criado de un prestamista, don Sancho, que sobrepasa el carácter acomodaticio y concupiscente del escudero cervantino homónimo. El intercambio del tratamiento subraya la inversión de la categoría social. Mientras que para el segundo la caridad se reduce al ritual tradicional de la limosna, el primero cree, idealistamente, en la hermandad universal evangélica. Expulsado de la Academia de Infantería de Toledo por solidarizarse con un compañero injustamente castigado, la siguió practicando con enfermos y pobres y como pacificador. A diferencia del impasible don Sancho, ayuda a una pobre madre con un hijo enfermo, empeñando su reloj. Trabajando ya para el prestamista, queriendo auxiliar a dos mujeres que iban a ser desahuciadas de un molino, una de ellas con un niño, agrede a los curiales. A consecuencia de ello, tras ser reducido por la Guardia Civil, es condenado a veinte años de prisión, donde todavía estaría al concebirse la narración, mientras que don Sancho es nombrado alcalde de Palma de Mallorca y condecorado con la Gran Cruz de Isabel la Católica.

Como ha sugerido Carola Duran (2002: 150), contribuye a que la narración se ambiente en Mallorca su insularidad, pensando en la ínsula Barataria, y sus molinos y el marco campestre propicia el Beatus ille (recreado en diversos pasajes del Quijote). El alcalde de Palma cuando Miró i Folguera contactó con Bartrina era Joan Antoni Perelló i Guinart, que ocupó el cargo desde el 1 de julio de 1879 hasta el mismo día de 1881, y, cuando la narración se publicó en La Ilustración Ibérica, Pascual Ribot i Pellicer, ambos del partido conservador ${ }^{45}$. De todos modos, no se puede asegurar ninguna alusión personal e incluso podría ser que la ubicación obedezca a la voluntad de rehuir referentes más próximos. En cualquier caso, no me consta que, por aquel tiempo, obtuviera la Gran Cruz de Isabel la Católica ningún alcalde de Mallorca, mientras que se concedió al de Barcelona, Enric de Duran i de Duran, también del partido conservador, el 4 de marzo de 1880, meses antes de la defunción de Bartrina.

borradores de un estudio en francés sobre Bartrina de su fondo citado, caja 5; Savine (1882: 444 y 1884: CXXXI); Rahola 1881; Gubernatis (1882: 543), incluso asociándolo a Hartmann (Gener 1881: 601 y 1883). O’Connor (1984: 393-394, 398 y 403) niega la influencia de Schopenhauer en Bartrina, aunque admite cierta similitud de temperamentos. En cualquier caso, este pensador era ya bastante conocido (Santiago 1990 y 1993; Moreno, L. F. 1994; Sotelo Vázquez 2001). Vale recordar el interés de Schopenhauer por el Quijote (Rius 1895-1904: III, 256-257; Parada 2004). Además, se ha interpretado esta novela schopenhauerianamente, como «voluntad y representación».

45. Gran Enciclopèdia Catalana. 5. Barcelona: Enciclopèdia Catalana, 1973, p. 189. 
Todavía se acordó de esta idea bartriniana Francisco Fernández Villegas (1895), con su conocido pseudónimo de «Zeda», a propósito de la Guerra de Cuba:

He leído, no sé dónde, que Bartrina, el gran humorista catalán, dejó entre sus papeles inéditos el plan de un cuento, cuyo asunto encierra una profunda y amarga verdad. Había imaginado el malogrado escritor pintar a Sancho, orondo y satisfecho, caballero en bien cebado caballo, llevando tras de sí, macilento y humillado, a guisa de escudero, a su antiguo amo. El trastrueque ideado por Bartrina se ha convertido en realidad. Sancho triunfa y don Quijote, el entusiasta, el soñador, el prototipo de nuestras antiguas virtudes, camina avergonzado y entristecido, soportando las burlas de todos los colegas de su improvisado señor ${ }^{46}$.

\section{CONCLUSIÓN}

El positivismo, además de contribuir al desarrollo del estudio documental y crítico de Cervantes, le reconoció una plasmación realista de la sociedad. Rechazada de entrada la reducción del cientificismo positivista al pedestre sentido común de Sancho, se cuestionó también la identificación de don Quijote con el idealismo, pero este personaje simbolizó a menudo la crisis del ideal romántico.

La aportación de Bartrina a la bibliografía sobre la presencia del Quijote en el teatro, publicada en 1876 en Cervantes, manifiesta su cervantinismo, su erudición - pretendiendo emular a dos conspicuos cervantistas, José M. Asensio y Leopoldo Rius, con un número considerable de añadidos-, su interés por dicho género y la música, su poliglotismo y su conocimiento de las literaturas castellana, francesa, italiana, inglesa y alemana de diversas épocas. Él mismo la enmarca en un estudio sobre la recepción de esta novela, para el que había tomado diversos apuntes, pero que no pudo realizar, como tantos otros propósitos. También encaja en este proyecto la referencia al Quijote del artículo sobre Alonso del Castillo Solórzano, publicado en 1870 en El Eco del Centro de Lectura.

No se editó ni se ha conservado ningún manuscrito de su intervención en la velada en homenaje a Cervantes celebrada en este ateneo en 1872, en que lo situó en la literatura europea, lo biografió y especuló sobre la autoría del Quijote de Avellaneda. Podrían ser de Bartrina, aunque sería aventurado atribuírselos, un par de escritos: uno relativo a este Quijote apócrifo, publicado aquel mismo año en el homenaje del Ateneo Tarraconense de la Clase Obre$r a$, con sus iniciales habituales - que, sin embargo, pueden corresponder a $\mathrm{J}$. M. de Barberà, muy relacionado con esta entidad-, y otro editado el año 
anterior, anónimamente, en El Eco del Centro de Lectura, sobre la admiración de Calderón por Cervantes, que se inscribiría también en el afán de estudiar la recepción cervantina. Otro proyecto de Bartrina, del que solamente conocemos el título, «Notas a algunas notas del Quijote», debía tratarse de unas sagaces apostillas a glosas de esta novela, seguramente a las de Hartzenbusch.

La narración «Sancho Panza», que he probado que no fue desarrollada por Josep Martí i Folguera, sino por su primo Josep Miró i Folguera, tiene un considerable interés, por la inversión del papel de este personaje y el de don Quijote, con la consiguiente sátira social, y por las dotes narrativas, aunque no se sepa hasta qué punto la esbozó oralmente Bartrina y su amigo fue fiel a su relato.

La presencia del Quijote en la obra literaria de Bartrina (una «Epístola» poética en que se parodia la célebre de «Urganda la desconocida» y tres pensamientos en verso o prosa) tiende a corresponder a la dialéctica entre la imaginación o el ideal y la razón o la realidad, con una insatisfacción de raíz romántica y un escepticismo justificado en términos positivistas. De todos modos, relativiza esta dicotomía ensamblando ambos personajes como dos aspectos del hombre, dualidad que Bartrina, en otros escritos, atribuye, darwinistamente, a la evolución, que no habría erradicado todavía la irracionalidad primitiva.

\section{APÉNDICES}

He actualizado plenamente la ortografía. Las leves modificaciones son las habituales en la adaptación de textos decimonónicos $\mathrm{y}$, con respecto a mi propósito, resultan irrelevantes, por lo que no las especificaré.

\section{Apéndice 1}

Joaquín María Bartrina (1876). «Bibliografía cervántica. D. Quijote en el teatro», Cervantes. 5, pp. 157-160.

Bibliografía cervántica. D. Quijote en el teatro

Sr. D. Leopoldo Rius

Muy Sr. mío:

Por una afortunada casualidad, llegó, hace pocos días, a mis manos un número de la acreditada revista Cervantes en el que, entre otros curiosos trabajos, figura una carta de V., dirigida al distinguido cervantófilo D. José María Asensio, en la que prueba, una vez más, sus conocimientos en bibliografía cervántica. 
A fin de contribuir a completar la lista, que, con las notas de V., debe ser ya numerosa, permítame que continúe algunas noticias, sacadas de unos apuntamientos que empecé hace algún tiempo, al proponerme estudiar los viajes póstumos de don Quijote, a quien la fama negó la tranquilidad de la tumba y que aún hoy anda recorriendo el mundo con universal contentamiento.

\section{FRANCIA}

1629. - Les folies de Cardenio, tragicomedia de Pichou, en 5 actos y en verso. La vi citada por Brunet al n. ${ }^{\circ} 16418$ de su Manual ${ }^{47}$. Recientemente he tenido el gusto de leerla en la antología Le théâtre Français au XVI et au XVII siècle, por É. Fournier (París: Laplace, Sánchez et $\left.C^{\text {ie }}, 1871\right)$. Según este laborioso colector advierte en una nota, hízose, algunos años después del de su estreno, un arreglo de esta tragicomedia, que se representó en el Teatro de las Tullerías. Luis $\mathrm{XV}$, que entonces era un niño, tomó parte en la representación.

1638. - Don Quichotte, comedia en 5 actos y en verso, de Guérin de Bouscal, que en

1641.- dio a la escena una segunda parte, con el título de Le gouvernement de Sancho [Pansa], comedia que, según veo en su lista, se cita en la 4. ${ }^{a}$ carta droapiana ${ }^{48}$. Mucho tiempo debió sostenerse con éxito en los teatros la primera de estas obras, pues la encuentro citada, entre las que estaban más en boga, en Le baron de la Crase, obra representada en $1662^{49}$.

1644. - En una casa particular, primero, y luego, a instancias del rey, en palacio, representose un ballet, de autor desconocido, titulado Le libraire du Pont-Neuf, ou Les Romans. El undécimo personaje que en él se presenta en escena es don Quijote, en cuya boca pone el poeta los siguientes versos ${ }^{50}$ :

Enflé d'une ardeur héroïque

Et d'un courage sans pareil,

J'ai rendue ma gloire publique

Et me suis fait cognoistre autant que le soleil.

On chante par toute la terre

Mes exploits d'amour et de guerre.

47. Jacques-Charles Brunet. Manuel du libraire et de l'amateur de livres. IV. París: Librairie de Firmin Didot Frères, Fils et $\mathrm{C}^{\mathrm{ie}}, 1863$, p. 633. Aportaré solamente los datos complementarios que estime imprescindibles.

48. He corregido «draopiana». En Siete cartas sobre Cervantes y el Quixote, dirigidas al muy honorable Doctor E. W. Thebussem, barón de Tirmenth. SS. TT. en los años de 1862 a 1868 por el señor M. Droap [Mariano Pardo de Figueroa]. Cádiz: Impr. de la Revista Médica, 1868, p. 13, se designa al dramaturgo como «Booscal» y se pospone el estreno a 1642, errores que mantuvo Rius (1876: 83).

49. Su autor es Raymond Poisson.

50. He enmendado la falta de concordancia sustituyendo «ella» por «él». 
Ainsi que mes desseins mon pouvoir est divin, Jusque là que mon bras, sans chercher d'assistance

Qu'en ma seule vaillance,

A répandu le sang de trente muids de vin.

Aparece luego Sancho Panza y dice, parodiando al ingenioso hidalgo:

Monté dessus une bourrique,

Avec un effroi sans pareil,

J'ai rendue ma honte publique

Et ne me suis co[u]ché non plus que le soleil.

On chante par toute la terre

Les exploits que j'ai faits au verre,

Jusque-la que mon nez n'est plus qu'un gros bouton;

Mais je ne suis repu que d'espoirs infertiles,

Car, lorsque on me promet des isles,

Je ne reçois jamais que des coups de baston.

Poco después, salen Cardenio y el Buscón (el protagonista de la novela de Quevedo) y, tras Gusman (Guzmán de Alfarache), pisan las tablas la Belle Égyptienne (la Gitanilla) y su amante ${ }^{51}$. Puede verse esta curiosa obra en la eruditísima de Víctor Fournel, Les contemporains de Molière ([París]: A. F. Didot, 1866, t. II, pág. 243).

1645. - Du Brosse hizo representar la comedia Le curieux impertinent.

1694. - Sancho Panza, comedia de Du Fresny.

1712. - Sancho Panza governeur, comedia en 5 actos y en verso de Dancourt.

1743. - EI compositor J. Bodin de Boismortier escribió una ópera en tres actos titulada Don Quichotte chez la Duchesse.

1743. - Poco debía soñar Cervantes al escribir la graciosa aventura del titerero que, más de un siglo después, en un teatro de títeres de París, había de representarse su ingenioso hidalgo. Y, no obstante, es así. Dedúcese de los escritos del eminente bibliógrafo M. de Soleinne que, en 1743 y probablemente durante las ferias de San Germán, se ejecutó un Don Quichotte, polichinelle, cuya letra escribió Valois d'Orville. Puede consultarse, para más detalles, la Histoire des marionnettes, que publicó el erudito Carlos Magnin en la Revista de Ambos Mundos primero (1850) y luego en un tomo, en casa Lévy 52 .

51. He pluralizado el último verbo para que concuerde con los sujetos coordinados.

52. París: Michel Lévy Frères, 1862, p. 167, en que se cita la entrada n. ${ }^{\circ} 3412$ de la Bibliothèque dramatique, de Soleinne. 
1762.- En 8 de julio (según Fétis ${ }^{53}$ ) se estrenó en el Teatro de la Ópera Cómica la obra en un acto Sancho Panza [dans son isle], música de Francisco A. Danican de Philidor (el célebre jugador de ajedrez).

1789.- En el Teatro de Monsieur se representó Le Nouveau Don Quichotte, música de Estanislao Champein.

1815.- Les noces de Gamache, ópera en 3 actos, música de Roberto Bochsa, representada en el Teatro de la Ópera Cómica ${ }^{54}$.

1864.- Don Quichotte de la Manche, por Victoriano Sardou. La crítica fue muy poco favorable para con la obra, en que quiso medir sus fuerzas el aplaudido dramaturgo francés.

Una deliciosísima comedia publicó en 1850 Próspero Mérimée, titulada Don Quichotte. No tiene absolutamente nada que ver con la creación de Cervantes ${ }^{55}$.

\section{INGLATERRA}

1694.- D'Urfey fue el primero que presentó al ingenioso hidalgo en el teatro inglés, escribiendo para el Teatro Real la 1. ${ }^{\mathrm{a}}$ y 2 . $^{\mathrm{a}}$ parte del Don Quijote [The Comical History of Don Quixote], que fue seguida en

1696. - de una 3. a parte. Una edición posterior de las tres obras debe ser la que V. posee.

1727.- En la noche del 13 de diciembre representose en el Teatro Drury Lane la comedia The Double Falsehood, en que Shirley desarrollaba un argumento tomado de los amores de Cardenio ${ }^{56}$.

173457.- En el Teatro Haymarket, se estrenó una comedia original de Fielding titulada Don Quijote en Inglaterra [Don Quixote in England], que se volvió a representar en el Drury Lane en 1752 y en el Covent Garden en 1759.

1793.- En 3 de agosto se puso en escena una obra, mezcla de tragedia, comedia y ópera (en cuya ejecución tomó parte el célebre Kean), titulada Mountaineers, fundada también en el episodio de Cardenio. Escribiola Coleman.

1846.- La ópera bufa de G. A. Macfarren [An adventure of Don Quixote] que V. dice haber visto anunciada en Inglaterra, se estrenó en el

53. F[rançois]. J[oseph]. Fétis. Biographie universelle des musiciens et bibliographie générale de la musique. VII. Bruselas: Meline, Cans et Compagnie, 1841, p. 227.

54. He corregido «Camache».

55. Ya he matizado esta afirmación en el estudio.

56. El autor es Lewis Theobald, aunque podría basarse en sendas obras del mencionado Shirley y de Shakespeare. Abunda la bibliografía sobre esta cuestión y sobre otras versiones de este narración de la primera parte del Quijote.

57. He corregido «1374». 
Teatro Drury Lane, en 3 de febrero de este año. Un hijo del compositor había escrito el libreto ${ }^{58}$.

1876. - En la noche del lunes 25 de septiembre, representose por primera vez en el Teatro de la Alhambra la ópera en 3 actos Don Quijote de la Mancha [Don Quixote], libro de Mess[rs]. Maltby y H. Paulton y música de Federico Clay. Los periódicos la anunciaron como una «grand comic and spectacular opera ${ }^{59}[\ldots]$ founded on incidents from Cervantes's celebrated novel». Alcanzó buen éxito $\mathrm{y}$, hasta hace pocos días, no se retiró de la escena. Entre los periódicos que se ocuparon de ella, debo citar la revista The Athenceum (n. ${ }^{\circ}$ 2553), que le consagró un curioso estudio bibliográfico, del que he sacado los anteriores datos ${ }^{60}$.

\section{ITALIA}

1770.- En Nápoles se representó Il Don Chisciotte ${ }^{61}$, con música del célebre Nicolás Piccini. El mismo autor había escrito en $1755 \mathrm{Il}$ curioso del suo proprio danno. ¿Sería El curioso impertinente? ${ }^{62}$

1772 a 1776. - Juan Paisiello, nacido en Tarento en $1741^{63}$, escribió un Don Chisciotte della Mancia, que se representó en Nápoles ${ }^{64}$.

1810? En este año, aproximadamente, escribió la música de la ópera Don Chisciotte [della Mancia] el conde de Miari, compositor poco conocido que nació en Belluno (Venecia) en $1787^{65}$.

1834 a 1836. - En el Teatro de La Canobbiana (Milán), dio a la escena Alberto Mazzucato su Don Chisciotte, ópera que hizo completo fiasco 66 .

... Severo Mercadante escribió también una ópera fundada en las aventuras del héroe manchego. Ignoro en qué año ${ }^{67}$.

58. Como se indica en la fuente, «Mr. F. Clay's 'Don Quixote'». The Athenceum. 2553, 30.

IX.1876, p. 441, el autor del libreto no fue el hijo, sino el padre, George, dramaturgo.

59. He marcado con puntos suspensivos entre corchetes la omisión de «in three acts».

60. «Mr. F. Clay's 'Don Quixote'». The Athenceum, 2553. 30.IX.1876, pp. 441-442. Bartrina escribió el título de la revista reduciendo «œ»» a «e».

61. He sustituido «Chisciotto» por «Chisciotte» en todos los casos.

62. En efecto.

63. He reemplazado «Tarrento» por la forma española habitual del pueblo italiano de «Taranto». Según diversas fuentes, este compositor nació el año anterior. Bartrina debió tomar la fecha del libro de Fétis mencionado, VII. Bruselas: Meline, Cans et Compagnie, 1841, p. 131.

64. Se representó por primera vez en 1769 en el Teatro dei Fiorentini de dicha ciudad.

65. Ciertamente, se ha fechado en 1810. He reemplazado «Bellune» por «Belluno». Bartrina debió tomar la adaptación francesa del topónimo italiano del libro de Fétis citado, VI. Bruselas: Meline, Cans et Compagnie, 1840, p. 408, dado que coincide en invertir las dos últimas cifras del año de nacimiento de Antonio Miari: 1778.

66. Se estrenó en dicho teatro en 1836.

67. Se estrenó en 1830, con el título de Don Chisciotte alle nozze di Gamaccio. 


\begin{abstract}
ALEMANIA
1771. - Antonio Salieri dio a conocer, en un teatro de Viena, una óperabaile en un acto de su composición, titulada Il Don Chisciotte . $^{68}$.

1791. - Según Fétis, en el almanaque de los teatros de Gotha de este año, se cita a Hubatschek como autor de la ópera en 3 actos Don Quijote [Don Quichotte ${ }^{69}$.

1811. - 20 de mayo. En el Teatro Nacional de Berlín, se representó una comedia en cinco actos titulada Die Aventuer der Ritter D. Quixote de la Mancha, en la que había algunas piezas musicales originales de Federico Luis Seidel.

1825. - Bajo el título de Die Hochzeit des Camacho ('Las bodas de Carmacho'), escribió una ópera en 2 actos el célebre Mendelssohn, que entonces solo tenía 16 años. Esta producción no tuvo éxito alguno y hubo de retirarse de la escena.
\end{abstract}

Deseando le sean de alguna utilidad los datos que acabo de apuntar, se ofrece de V. S. S.

JOAQUÍN MARÍA BARTRINA

Barcelona, 2 de diciembre de 1876.

\title{
Apéndice 2
}

Parto de la versión de José Miró Folguera ([1893]). El ratoncito. Barcelona: La Publicidad, respecto a la cual anoto las variantes de Joaquín M[aría]. Bartrina y J[osé]. M[iró]. Folguera (1885). «Don Sancho Panza», La Ilustración Ibérica. 154, pp. 795 y 798-799.

\section{Don Sancho Panza}

\section{Advertencia}

Pocos meses antes de morir Joaquín María Bartrina - a las postrimerías del año 1879 - , pasaba yo a su lado la mayor parte de los días. La enfermedad horrenda que corroía su cuerpo estaba entonces en su paroxismo. Bartrina vivía encerrado en su casa de la calle de Tallers y aminoraba la tristeza de sus soledades la compañía de su familia y de los escasos amigos que le visitaban. Yo trabé con él amistad por aquel entonces y mi espíritu, conturbado por la negrura del pesimismo que a la juventud sugieren las primeras contra-

68. Se titula Don Chisciotte alle nozze di Gamace, consta de dos actos y se representó en el Burgtheater.

69. F[rançois]. J[oseph]. Fétis. Biographie universelle des musiciens et bibliographie générale de la musique. V. Bruselas: Meline, Cans et Compagnie, 1839, p. 206. 
10 riedades del mundo, encontraba un acre deleite en el trato de aquel joven envejecido, sin vigor en el cuerpo y muerto el espíritu para la vida real, que consideraba una serie incesante de desdichas. Como si la enfermedad le diese nuevos alientos, el espíritu de Bartrina se aguzaba más y más, se fijaba con curiosidad insaciable en los fenómenos inexplicados de la naturaleza, inven-

15 taba teorías y planteaba sistemas, enamorado de todo lo hipotético y oscuro. Entre nosotros se estableció una comunión absoluta de ideas y de sentimientos. Muchas veces conversábamos en voz baja y, saturados ambos de los ideales abstractos y engañosos de justicia y de virtud, uníamos nuestras protestas contra la organización natural y acudían a nuestros labios las quejas

20 amargas de Leopardi, las nihilistas tendencias de Schopenhauer o, a semejanza de Hartmann, demostrábamos nuestro aborrecimiento a la conciencia, que distingue al hombre superior y que es la madre del dolor en la vida.

A medida que la enfermedad iba devorando los restos de aquel cuerpo anémico, Bartrina iba cobrando mayor singularidad, hasta aparecer en todo el

25 espantoso relieve de su personalidad extraordinaria.

Le estoy viendo aún, como en aquellas tardes grises de diciembre, informe entre la penumbra, encorvado su cuerpo flaquísimo sobre una mesita con tapete de crochet y hablando sin cesar con aquella voz apagada de timbre tan suave y penetrante, o, como en las largas veladas, iluminado por la luz cruda

30 del quinqué que delataba todos los martirios que la naturaleza injusta le infligía.

La antítesis suprema de aquel organismo, monstruoso desde su generación, estaba allí visible, brutal. El cuerpo, que había sido siempre débil, se pudría lentamente. La sangre no regaba los órganos con sus benéficas oleadas, la tos

35 sacudía bruscamente el pecho aplastado y la carne se descomponía y empujaba el pus hacia afuera en tumores turgentes como bolas de metal. La piel de la cara de silueta romana estaba arrugada y amarilla como un pergamino viejo. Las demacradas facciones aparecían encuadradas en el marco negro de una venda de seda que sostenía la quijada y tapaba la horrorosa podredumbre

40 de los abscesos abiertos e incurables. Y, en medio de aquella cabeza de momia desenterrada, brillaba un solo ojo - entornado penosamente el otro bajo el peso de un tumor-, un ojo saliente y grande, de expresión siempre tierna y tranquila, como la de los ciervos, exhalando de repente una mirada profunda y preñada de ideas.

45 La vida que huía del cuerpo se concentraba más y más en el espíritu. El divorcio eterno que existía entre el temperamento inactivo y el cerebro incansable se presentaba completo y el pensamiento en que Bartrina reasumía toda su personalidad tenía prueba evidente: «iQué dulce y ligera es la concepción! ¿Qué difícil y penoso es el parto!», exclamaba Bartrina. Y entonces le veíamos

50 concibiendo sin cesar dramas y novelas, experimentos físicos y poemas, cuentos y estudios de crítica, sin que su mano huesosa y exangüe tuviese fuerza bastante para fijar en el papel las ideas que forjaba su entendimiento.

Algunas de estas ideas, esbozadas en conversación íntima, recogí, que acuden de vez en cuando a mi memoria y me renuevan el deleite de los co- 
55 loquios con el pobre difunto, de la comunión ideal que me producía goces inefables en aquellos momentos en que nos adivinábamos nuestras mutuas ideas y confundíamos nuestras aspiraciones.

Todo esto se me ha soltado de la pluma a propósito de una pequeña narración que Bartrina delineó y que voy ahora a escribir por primera vez,

60 componiéndola con algo mío, pero dejando siempre a mi amigo el mérito de la primera invención. Sirva esta colaboración póstuma de homenaje a la memoria de Joaquín María Bartrina.

Don Sancho Panza es uno de los más acreditados prestamistas de Palma de

65 Mallorca. Su cuerpo rechoncho, su cara abotargada y rubicunda, sus ojos pequeños, como esmaltados, declaran la placidez indiferente del hombre ahíto que no debe pensar en mañana ni acordarse de ayer. Heredó de su padre la caja de préstamos, un temperamento robusto, una hacienda que en cereales y aceite daba una renta algo crecida y una cabeza dura como una roca. Su fuerte es no

70 saber inventar nada, con lo que ha alcanzado sus cuarenta años sin un disgusto ni una enfermedad. No hay lugar común ni frase ramplona desgastada por el uso que se le escape: dice siempre lo que han dicho todos y habla de política después de leer el diario. En él se ha acumulado toda la insignificancia de la clase media y todo el horror a lo que puede alterar una costumbre o borrar un

75 vicio. Don Sancho almuerza a las diez un par de huevos fritos, come a las dos un puchero compuesto de modo invariable, un principio en que alternan las primicias de la huerta con la carne y un postre delicado y cena, por último, a las ocho en punto, saboreando con preferencia de la mar el mero, de la tierra el carnero y del bosque la perdiz, como él dice con énfasis teatral y sonriéndo-

80 se al acabar, a modo de aplauso callado. Practica la caridad a su modo, dando cinco céntimos todos los sábados a un ciego gangoso que cobraba ya la renta en vida del padre de Panza, va a misa los domingos a medio día, de levita holgada y sombrero de copa, se ríe de los curas por lo mucho que entienden la vida y no lee jamás libro ninguno fuera del negocio.

85 Tal es el bueno de don Sancho Panza - del comercio-, Palma de Mallorca.

En una cosa ha faltado a la tradición, y es en no casarse como lo hizo su padre. Pero don Sancho ha creído así cometer una falta menor, pues, con una mujer en casa, todo andaría revuelto y se romperían las costumbres tranquilas en que vive encerrado.

90 Estaba, pues, un día don Sancho en su despacho, caladas las gafas negras con que preserva la vista del cansancio, dibujando números en sus libros y despachando a los que le traían algo que empeñar, porque él se pasaba sin dependientes de escritorio y por sí mismo llevaba todo el peso de los negocios.

Entró, en esto, en el despacho una mujer demacrada, con un niño escro-

95 fuloso montado en un brazo y cogido en el otro un hato de ropa. Levantó la cabeza el prestamista, lanzó a la mujer una rápida mirada y volvió en seguida a sus números, con el descuido del que se encuentra con un amigo antiguo.

— ¿Es usted? ¿Qué hay? — dijo al propio tiempo. 
100 - Pues, ahí le traigo eso. Son dos sábanas nuevas de hilo. He de comprar la medicina para el niño y necesito un duro.

— ¡Jem!... me parece que no podrá ser. A ver, a ver eso... No me es posible dejar más de doce reales. Ya ve usted: ahí tiene los pendientes de hace dos meses y el mantón que se está pudriendo. Lo dicho, doce reales.

105 - ¡Don Sancho!... — gimió la mujer con los ojos arrasados.

Iba a decir algo cuando entró en el despacho un mozo de unos treinta años, alto, flaco, avellanado, envuelto en un gabán descolorido y reluciente, cubierta la cabeza con un sombrero grasiento y, mal liada al cuello sucio de la camisa, una corbata vieja con el lazo caído y lastimero. Al ver que el presta110 mista estaba ocupado, se quedó junto a la puerta esperando su turno.

— ¡Don Sancho!... — repitió la mujer bajando la voz, mientras rodaba por su cara una lágrima silenciosa, que se disolvió luego en el hombro del chiquillo-. Mire usted que lo necesito más que para comer: ¡Lo necesito para mi hijo que se muere!

115 -No me cuente usted desdichas, que bastantes me han contado. Si quiere usted dejar las sábanas, tome usted doce reales. Si no, recoge usted eso y tan amigos como antes.

La mujer se quedó muda, inmóvil. Una tras otra, sus ojos iban derramando lágrimas, que caían sobre el niño como una lluvia pausada. De pronto, el

120 recién llegado avanzó con resolución y tiró sobre la mesa un reloj de oro.

-Es remontoir ${ }^{70}$, con 15 rubíes. Deme usted lo que quiera - dijo con voz apagada y ronca. Y dirigiéndose a la mujer, añadió-: No se vaya usted, todo se compondrá.

Don Sancho se quedó mirando fijamente al desconocido un buen rato.

125 Luego abrió el reloj por los dos lados, estudió la máquina, las tapas y dijo después:

- Puedo darle a usted quince duros.

- Vengan.

- Ahí tiene usted la papeleta.

130 - Bueno, bueno, deme usted el dinero.

Lo cogió, alargó diez duros a la mujer que le contemplaba atónita, cargola con el hato de las sábanas y la empujó suavemente hacia la puerta.

-Ahora ya puede usted marcharse.

— ¡Oh, caballero!... ¡Oh!... — pero la mujer no pudo decir más, porque el 135 desconocido la había llevado a la escalera y había cerrado la puerta tras ella. Al volver al centro del despacho, centelleaba una lágrima, redonda y brillante como una gota de mercurio, en la manga del polvoriento gabán.

El desconocido vio la gotita y la diluyó suavemente entre sus dedos con delicada ternura.

140 Don Sancho Panza no había visto caso igual en todos los días de su vida. Con las gafas pegadas a la frente — semejantes a dos agujeros abiertos en las

70. Reloj con un mecanismo, llamado también así, que, como indica el galicismo, eleva el peso o arma el muelle, lo que permite la puesta en hora. 
tinieblas de aquella cabeza hueca-, cogida la pluma entre sus dedos, clavado en el viejo sillón de brazos, no sabía qué pensar, ni qué decir, ni qué hacer. Se encontraba en la oscuridad absoluta.

145 El desconocido había apoyado el codo derecho en la repisa del tabique de tablas y cristales que separaba el prestamista de sus clientes y, con la mirada fija en la puerta, parecía aún estar viendo a la mujer y al niño y les sonreía con una sonrisa de compasión y de ternura, que fundía todas las arrugas de su cara.

150 Por fin salió don Sancho de su oscuridad y preguntó al del reloj:

- ¿Conoce usted a esa mujer?

Estremeciose el otro, como despertando de un profundo sueño, y exclamó:

— ¿Eh?... ¡Ah!... ¿Que si la conozco?... Es una hermana mía. Puedo socorrerla y lo hago.

$155-$ Si es una hermana, se comprende. ¿Entonces será usted de Palma? ¡Es extraño! ¡No recuerdo haberle visto jamás!

— ¡No, si yo no soy de Palma! No sé quién es esa pobre madre. Digo que es hermana mía porque todos somos hermanos en este mundo.

— ¿Cómo es eso?

160 - Jesucristo lo dijo y el corazón nos lo repite a cada momento. Yo así lo he creído siempre y he hecho cuanto me ha sido posible para demostrarlo. He sido pobre, lo soy y continuaré siéndolo probablemente, pero ¿qué importa ser pobre de bienes cuando se es rico de emociones suaves y consoladoras? Ahora mismo, no puede usted figurarse cuánto he gozado pudiendo socorrer

165 a la infeliz que estaba ahí desesperada sin poder curar al hijo de sus entrañas. El dinero que la he dado representa la mayor parte de mis últimos recursos, pero ¿acaso no estoy yo sano para poder ganarlo con mayor facilidad que esa madre desvalida?

Durante toda mi vida he estado haciendo lo mismo, y no me arrepiento.

170 Mire usted, a la edad de quince años ingresé en la Academia de Infantería y, ya próximo a salir, me expulsaron, porque, al ver injustamente castigado a uno de mis compañeros, protesté con toda la viveza de mi carácter ante el director, lo que fue juzgado como un acto de indisciplina. Volví a mi casa y a los pocos meses moría mi padre, único representante de una noble familia

175 de la Mancha. El patrimonio, mermado ya en la juventud de mi padre, quedó reducido a nada después de pagar a los muchos acreedores que tenían hipotecadas la casa solariega y unos prados que nos quedaban. Me encontré, pues, en la miseria y fui a Madrid a trabajar. Mas, por una fatalidad extraña, jamás he podido hacer fortuna ni llegar siquiera a un bienestar relativo. Verdad es

180 que tampoco he dado mucha importancia a eso, pues he preferido tener satisfecha a mi conciencia y lograr los goces inefables que al alma proporciona la caridad. He servido voluntariamente en un hospital de coléricos, he auxiliado a los pobres, he impedido todas las riñas que he presenciado, a costa de mis espaldas casi siempre. He procurado, en fin, practicar la doctrina del amor a 185 nuestros hermanos que sufren.

-Y ahora, ¿qué va usted a hacer? 
— iQué sé yo! He venido a Palma recomendado a un comerciante que hace ocho días se trasladó a Argel. No conozco a nadie, pero, como nunca perdí la esperanza ni me arredra el trabajo, buscaré algo en que ganarme el sustento.

190 Don Sancho estuvo un momento silencioso y luego dijo vivamente a su interlocutor:

- ¿Quiere usted quedarse en mi casa?

- Con mucho gusto.

- Yo necesito un joven de confianza, que cuide de arreglar las prendas,

195 de tenerlas bien conservadas, de sacar las que le pida y de colocar las que vayan llegando. Como ve, la cosa es sencilla. El muchacho que tenía se marchó anteayer y no sé por qué, pero usted me inspira confianza. Usted vivirá aquí, corriendo todo de mi cuenta y además le daré seis duros al mes. ¿Le parece bien?

$200 \quad$ ¡Y Y lo creo! Perfectamente.

- Bueno, pues voy a enseñarle en un momento lo que debe hacer. ¡Ah! ¡No me ha dicho aún su nombre!

-Es verdad. Me llamo José de Quijana y Salazar. En la Academia y en Madrid, era más conocido, sin embargo, por «Quijote».

Así entró Quijote al servicio de don Sancho Panza. El prestamista estaba contento de su dependiente, que cumplía todas las órdenes con diligente puntualidad, aunque de vez en cuando le disgustaba con sus extravagancias. Cuando entraba un pobre a empeñar sus últimos harapos, ya podía tener por

210 seguro don Sancho que Quijote intercedería para que le diese algún dinero y, como eso sucedía con frecuencia, el prestamista necesitaba echar mano de todo el caudal de su paciencia para soportar a aquel moscón inaguantable. Una vez llegó hasta a hacer un mal negocio para quitárselo de encima.

Quijote estuvo treinta días enfermo del tifus que cogió velando durante 215 varias noches a un vecino pobre, viudo y con hijos. Una noche, después de cenar, compareció con un negro a quien había encontrado vagando y que no tenía donde dormir. Don Sancho le toleró que se quedase en casa y el negro pagó el hospedaje llevándose dos cubiertos de plata.

Transcurrieron días y días sin que se alterasen las amistades del amo y el 220 criado, que continuaba tan poco conocedor del mundo y tan incauto en su generosidad como siempre.

En esto, don Sancho empezó a alarmarse, porque el arrendatario de su hacienda no había pagado la anualidad del arriendo ni daba señales de querer hacerlo. Vencía el arriendo por San Jaime y había pasado un mes sin ver la

225 cara al arrendatario ni recibir noticias suyas. Don Sancho, como hombre práctico que era, resolvió ir a encontrarle a la hacienda misma.

Como el carricoche de su propiedad estaba muy desvencijado, pensó hacer el camino montado en la Perla, una yegua vieja y soñolienta, más pausada en su marcha que mula de obispo. En cuanto a Quijote, que debía acompañarle 230 por lo que pudiese tronar, se acomodaría en el asno del chocolatero de la esquina, quien se lo prestaría buenamente para la ocasión, como en efecto lo hizo. 
Quedó todo dispuesto y a los primeros albores del día estaban don Sancho y Quijote fuera de las puertas de la ciudad. Sobre el fondo rojo de oriente, destacaban las siluetas oscuras del amo y del criado: delante, aquel sobre la

235 yegua oronda y reluciente, y, detrás, Quijote, montado en un asno lamentable, uno de estos asnos de mayor talla, de orejas grandiosas, flaquísimo, todo huesos, víctima precoz de un trabajo sobrecargado.

Mientras don Sancho dormitaba, embelesaba a Quijote la hermosura de aquella madrugada de verano: la riqueza de colores del cielo, sembrado de 240 nubes candentes hacia levante, que se atenuaban en tonos rosados suavísimos hasta disolverse en el azul del zenit. La tierra toda se bañaba en las tintas claras del cielo y aparecía agradable a la vista, sin las crudezas del mediodía. Quijote se deleitaba contemplando tanta maravilla, viendo como el horizonte se iluminaba con reflejos de fuego, precursores del sol, mientras acariciaba a

245 sus oídos la música del agua que mansamente corría por una acequia vecina a la carretera, con armonías cristalinas, como de cascadas de diamantes, que resonaban entre el silencio universal o acompañaban el chillido alborozado de un gorrión que atravesaba el aire aleteando a borbotones. A lo lejos, algunos molinos de viento tendían al cielo sus brazos de palo, como gigantes en oración.

250 Desperezose, al fin, don Sancho, al sentirse en la cara el beso tibio del sol, que se levantaba en el horizonte. Dirigió en seguida su cabalgadura al primero de los molinos de viento, habitado por una familia conocida suya, a fin de calmar las ansias de su estómago en ayunas. Siguiole Quijote y, al poco rato, llegaron al molino, de donde salieron a recibirles el molinero y su mujer.

255 Descabalgaron los viajeros, descargó Quijote al asno de una alforja repleta y, en santa paz, empezaron amo y criado a comer debajo de un emparrado pegado al molino.

Cogió el molinero algunos racimos de uva temprana que de la parra colgaban y los presentó a sus huéspedes, que los encontraron exquisitos. Quijo260 te paladeaba las uvas con delicia y, con un grano cogido entre dos dedos de la mano derecha, dijo:

- ¡Dichoso mil veces quien puede gozar a todas horas la vida del campo! ¡Dichoso quien puede admirar a Dios en la maravillosa ordenación de sus obras! ¡Cómo alegran el alma los espectáculos de la naturaleza! ¡Cómo incli-

265 nan el corazón hacia la paz y la caridad! Antes de esta época nuestra de egoísmo y de lucro, se apreciaban los goces de la vida entre valles y montañas y no se amontonaba la gente en inmensas ciudades oscuras y sucias. El canto de los arroyuelos, la melancolía de las puestas de sol, el susurro de las mieses doradas que ondulan al compás de la brisa, los colores inimitables de 270 rosas y claveles inspiraban a los poetas odas sonoras que levantaban el espíritu. En el campo se ve la prodigalidad de la Providencia, que provee de alimento a los pajaritos del aire y a las bestias de la tierra y se aprende a socorrer al necesitado y al huérfano. En el campo transcurren las estaciones con regularidad asombrosa y traen, con su venida, espectáculos siempre nue275 vos que dan norma para una vida ordenada y sana. En el campo, por fin, se aprende a amar a Dios y a los hombres. 
Los molineros escuchaban con la boca abierta la peroración de Quijote y don Sancho le prestaba también atención. Al terminar, dijo el amo:

— ¡Lástima de chico! ¡Haría un buen predicador! Pero, dejémonos de 280 floreos y vámonos, que es tarde.

En efecto, era ya bastante entrado el día cuando don Sancho y Quijote montaron otra vez en sus cabalgaduras y se despidieron de los afables molineros.

No habían andado mucho cuando don Sancho, señalando un molino próxi285 mo con el brazo tendido, dijo a Quijote:

- Vea usted las dulzuras del campo. Ahí sacan muebles por la ventana, lo que, por lo visto, es un lanzamiento.

_ $\mathrm{O}$ Oh! ¡Hay una mujer que llora! ¡Y esos canallas vestidos de negro, tiran sillas y ropas por la ventana! ¡Ahora sacan a empellones a otra mujer y a un 290 niño! ¡Ah, cobardes! ¿Así se atropella a una mujer indefensa?... ¡Bandidos!

$\mathrm{Y}$, dando taconazos al asno, logró hacerle tomar un paso entrecortado o casi galope.

— ¿Pero a dónde va usted? - le gritó don Sancho- ¡No sea usted niño! ¿Que me va a comprometer! ¿Quijote!

295 Mas Quijote no hizo caso y continuó tan aprisa como pudo en dirección al molino.

Al poco rato estaba allí $\mathrm{y}$, entre la sorpresa general, empezó a repartir puñetazos en medio de los curiales que cumplimentaban el desahucio. El escribano cayó en redondo de una puñada en la cara y dio de cabeza en un

300 grueso pedrusco. Corrió la sangre sin que Quijote se calmara. Antes al contrario, no paró hasta que puso en fuga a todos los servidores de la justicia. Consoló lo mejor que supo a las dos desgraciadas mujeres, muertas de miedo al ver al escribano desangrándose en el suelo, y estaba pensando un plan para sacarles de los apuros del momento cuando se presentó una pareja de la Guar-

305 dia Civil, acompañada de los alguaciles. Sin escuchar sus protestas, le ataron codo con codo, levantaron al escribano, que no había muerto, pero tenía una herida de consideración, le cargaron en el asno de Quijote y regresó toda la comitiva a Palma. Don Sancho había desaparecido.

Quijote estuvo en la cárcel mientras duró el sumario, que el señor juez dio 310 por concluso en menos de dos años, y luego fue condenado por la audiencia a veinte años de presidio, donde está aún y donde debería haber estado siempre.

Don Sancho Panza es actualmente uno de los más respetables personajes de Palma de Mallorca, alcalde constitucional de la ciudad y gran cruz de Isabel la Católica, que el gobierno acaba de concederle por los grandes ser315 vicios prestados al país.

1 Las abreviaturas de «don» y de «usted» se alternaban, incoherentemente, con las palabras completas, por lo que las he desarrollado 5 en su paroxismo] en todo su desarrollo 9 sugieren] dan 12 Como] Y como 23 devorando] devorando más y más 27 encorvado] inclinando // sobre] hacia 38 viejo] comido 40 abscesos] En ambas versiones, se omite la primera $\mathrm{s} \quad 45 \mathrm{La}$ vida] toda la vida 59 delineó] me contó 62 Bartrina] Bartrina talento robusto, asesinado por la anemia del cuerpo, que le arrebató a la vida en la edad que más valiosas obras produce.- J. M. F. 66 como esmaltados] saltones 
y de mirada insignificante // declaran] delatan 78 mero] Corrijo nero 89 encerrado] encerrado como el caracol en su concha 99 usted] usted, Cecilia 101 un duro] doce reales 103 doce] seis 104 doce] seis 105 arrasados] húmedos 107-108 cubierta la cabeza] con la cabeza cubierta 109 lastimero] lastimero como un sauce llorón 111 bajando la voz] Om. 123 compondrá] arreglará 124 al] la, errata 130 el dinero] los quince duros 131 Lo cogió] Cogió el dinero 136 lágrima] bolita 137 gabán] gabán, era una lágrima que había saltado sobre su brazo al empujar a la mujer hacia fuera 141142 las tinieblas] los abismos negros 142 hueca] vacía 143 hacer] hacer. No comprendía nada, no veía nada. 145-146 el codo derecho en la repisa del tabique de tablas y cristales que separaba el prestamista de sus clientes] una mano en la esquina de la mesa 147 les] la 148 que fundía] en la que se fundían 161 he hecho cuanto] hecho lo que 166 la] Mantengo el laísmo 167-168 esa madre desvalida] aquella pobre madre 169 Durante] $\mathrm{Om}$. // estado haciendo] hecho 171 ya] cuando estaba // me expulsaron] fui expulsado 172 protesté] protesté abiertamente y 177 la casa solariega] las casas solariegas 178-179 jamás he podido] no he podido jamás 181 lograr] buscar 183 pobres] desvalidos 188 se trasladó] trasladó su establecimiento // nunca perdí] jamás he perdido 194 cuide] cuied, errata 203-204 En la Academia y en Madrid, era más conocido, sin embargo, por] pero en todas partes, desde muchacho, me han llamado 207 contento] satisfecho 212 a] Om. 214 treinta] quince 218 plata] plata, a la mañana siguiente 220 incauto] vacilante 224 Jaime] Juan // había pasado un mes] habían pasado quince días 227 muy desvencijado] descompuesto 232 dispuesto] arreglado 234 destacaban] se destacaban 237 precoz] Om. // sobrecargado] sobrecargado, que le había quitado las fuerzas en la flor de su edad 238 dormitaba] dormitaba sobre su pacífica cabalgadura // embelesaba a Quijote] Quijote admiraba 240 hacia] en 241 disolverse] diluirse // azul] azul claro 244-245 mientras acariciaba a sus oídos la música] a su oído llegaba incesante el rumor 247 chillido alborozado] alegre chillido 248 aleteando a borbotones ] batiendo con fuerza las alas 249 cielo] aire 250 la cara] su rostro 251 que] que, como una hostia candente 252 habitado por] donde vivía // a fin de] para 254 de donde salieron] y les salió. Se corrige, pues, la falta de concordancia // recibirles] recibir $255 \mathrm{los}$ ] los dos 258 de uva temprana que] Om. 258-259 colgaban] Om. 260 paladeaba] paladeaba el zumo de 267-268 El canto] La música 270-271 espíritu] espíritu y encendían el amor a la naturaleza 278 dijo] le dijo // el amo] $O m .280$ floreos] retóricas // vámonos] vámonos ya 281 era] estaba // entrado] adelantado 286 Vea] Mire 287 lanzamiento] desahucio 288 esos canallas] aquellos hombres // tiran] echan 289 ropas] cajones // empellones] empujones 293 a] Om. 295 tan aprisa como pudo] Om. 298 puñetazos] empellones y puñetazos // en medio de los curiales] a los dos o tres alguaciles y al escribano // cumplimentaban] dirigían 309-310 que el señor juez dio por concluso en menos de dos años] Om. 314 concederle] cederle 315 al país] Sin cursiva // Sin firma] JoAquín M. ${ }^{a}$ Bartrina. J. M. Folguera.

\section{BIBLIOGRAFÍA CITADA}

Alonso Asenjo, Julio (2005). «Vuelta a la interpretación romántica del Quijote», Tirant. 8. Accesible en: <http://parnaseo.uv.es/Tirant/Butlleti.8/Alonso_Quijote_Vuelta.htm\#ftn1>.

Armero Alcántara, Álvaro (2005). Visiones del Quijote. Sevilla: Renacimiento.

Arqués, Rossend (1986). «El "leopardisme” de J. M. Bartrina. ¿Mite o realitat?», Rassegna Iberistica. 25 , pp. 19-30.

Arús i Arderiu, Rossend (1880). «En Joaquim M. ${ }^{a}$ Bartrina», La Llumanera de Nova York. 66, pp. 5-7. Se conserva un manuscrito de este artículo, con correcciones, en la Biblioteca Pública Arús, de Barcelona (Arús II-c2/35).

Asensio, José M. (1874). «Cervantes inventor», en Academia Sevillana de Buenas Letras. Conmemoración del CCLVIII aniversario de la muerte de Cervantes, en el día 23 de abril de 1874. Sevilla: Baldaraque, pp. 11-33.

Bacardí, Montserrat e Imma Estany (2006). El Quixot en català. Barcelona: Publicacions de l'Abadia de Montserrat.

Balzer, Berit (2004-2006). «Una mirada poética sobre el nacimiento de la novela: el prólogo de Heinrich Heine a una edición alemana del Quijote», Tropelías. 15-17, pp. 203-212. 
Bartrina, Joaquín María (1870a). «Alonso del Castillo Solórzano», El Eco del Centro de Lectura. 7, pp. 2-4.

Bartrina, Joaquín María (1870b). «Don Juan Tenorio», El Eco del Centro de Lectura. 17, pp. 3-4.

Bartrina, Joaquín María (1870c). «Curiosidades», El Eco del Centro de Lectura. 18, pp. $3-4$.

Bartrina, Joaquín María (1874a). Algo. Colección de poesías originales. Barcelona: Imprenta de la Renaixensa.

Bartrina, Joaquim Maria (1874b). «De mon infern», La Renaxensa. 14, p. 175. Reproducido en El Eco del Centro de Lectura. 15, 30.V.1877, p. 8.

Bartrina, Joaquín María (1876). «Bibliografía cervántica. D. Quijote en el teatro», Cervantes. 5 , pp. 157-160.

Bartrina, Joaquín María (1877). Algo. Colección de poesías originales. Barcelona: Librería Española.

Bartrina, Joaquín María (1881). Obras en prosa y verso. Barcelona: Teixidó y Parera.

Bartrina, Joaquín M[aría]. y Rosendo Arús y Arderiu (1887). El nuevo Tenorio. Leyenda dramática en 7 actos, en prosa y verso, $2^{\mathrm{a}}$ ed. Madrid: Florencio Fiscowich.

Bartrina, Joaquín M[aría]. y J[osé]. M[iró]. Folguera (1885). «Don Sancho Panza», La Ilustración Ibérica. 154, pp. 795 y 798-799.

Bastons i Vivanco, Carles (2004). «Andanzas de Don Quijote y El Quijote por la Cataluña modernista», en Magdalena León Gómez (ed.), La literatura en la literatura. Actas del XIV Simposio de la Sociedad Española de Literatura General y Comparada. Alcalá de Henares: Centro de Estudios Cervantinos, pp. 85-96.

Cabré i Monné, Rosa (2002). «Joaquim Maria Bartrina, un mite. Creació i evolució», en Montserrat Corretger y Xavier Ferré (eds.), Joaquim M. Bartrina, entre les raons poètiques i les cientifiques. Reus: Publicacions de l'Arxiu Municipal de Reus, pp. 15-49.

Cabré i Monné, Rosa (2012). Notas a Joaquim M. Bartrina, Cor infinit i altres poemes. Lérida: Punctum.

Centre de Lectura (1900). El Centro de Lectura a D. Luis Quer Cugat. Corona fúnebre. Reus: Imp. de C. Ferrando.

Cervantes Saavedra, Miguel de (2015). Don Quijote de la Mancha, dir. Francisco Rico. Madrid: RAE.

Close, Anthony (2005). La concepción romántica del Quijote, trad. de Gonzalo G. Djembé. Barcelona: Crítica.

Colom i Bussot, Juli (2012). Josep Roca i Roca. Polític, periodista i escriptor republicà: Els anys de joventut, 1848-1878, Pere Gabriel (dir.). Tesis doctoral. Universitat Autònoma de Barcelona.

Corretger, Montserrat (2012). «Joaquim M. Bartrina: poeta i tèoric de la Revolució», en Montserrat Corretger, Al marge: escriptors catalans del segle XIX. Benicarló: Onada Edicions, pp. 61-92.

Cuevas Cervera, Francisco (2011). «La Crónica de los Cervantistas, única publicación que existe en el mundo dedicada al príncipe de los ingenios (1871-1879)», en Christoph Strosetzki (coord.), Visiones y revisiones cervantinas. Actas selectas del VII Congreso Internacional de la Asociación de Cervantistas. Alcalá de Henares: Centro de Estudios Cervantinos, pp. 257-266.

Cuevas Cervera, Francisco (2015). El Cervantismo en el siglo XIX: del Quijote de Ibarra (1780) al Quijote de Hartzenbusch (1863). Oviedo: Universidad de Oviedo.

Cuevas Cervera, Francisco (2016). «Lectura decimonónicas de la segunda parte del Quijote: una aparente paradoja del cervantismo romántico», Edad de Oro. 35, pp. 121-134. http://doi.org/10.15366/edadoro2016.35.006. 
Duran, Carola (2002). «Algunes idees de Bartrina, recollides pels seus amics», en Montserrat Corretger y Xavier Ferré (eds.), Joaquim M. Bartrina, entre les raons poètiques $i$ les cientifiques. Reus: Publicacions de l'Arxiu Municipal de Reus, pp. 137-167.

Escobedo, Joana (1981). «El teatre de Josep Roca i Roca. Aportació documental coetània», Affar. 1, pp. 69-85.

[Fernández Villegas, Francisco] «Zeda» (1895). «Dos de Mayo», Los Lunes del Imparcial. 29.IV.1895, p. [1].

Ferré Trill, Xavier (2007). Pensament positivista a Catalunya. Valls: Cossetània.

Ferré Trill, Xavier (2013). ¡Guerra a Dios! de Joaquim M. Bartrina acompanyat de Dios de Francesc Sunyer i Capdevila. Tarragona: Publicacions URV.

Finello, Dominick (1987). «Notes on Nineteenth-Century Quijote Scholarship», Bulletin of the Cervantes Society of America. VII (1), pp. 59-69.

Fontanals i Jaumà, Reis y Marga Losantos (2007). Biblioteca de Catalunya 100 anys. 1907-2007. Barcelona: Biblioteca de Catalunya.

García Barrón, Carlos (1981). «El Quijote según Manuel de la Revilla», en Manuel Criado de Val (ed.), Cervantes, su obra y su mundo. Actas del I Congreso Internacional sobre Cervantes. Madrid: Edi-6, pp. 909-914.

Garrido Ardila, J[uan]. A[ntonio]. (2014). «El Quijote en el teatro inglés del siglo XIX», Anales Cervantinos. 46, pp. 41-66. https://doi.org/10.3989/anacervantinos.2014.004.

Gener, Pompeyo (1878). «Dos tipos españoles: don Quijote y don Juan» y «Deux types espagnols: don Quichotte et don Juan», L'Alliance Latine, pp. 19-25.

Gener, Pompeyo (1881). «La littérature espagnole au XIX ${ }^{\mathrm{e}}$ siècle», Le Livre. II (1), pp. 598-602, del que se conserva un manuscrito en la caja 12 de su fondo del Arxiu Històric de la Ciutat de Barcelona. Integrado parcialmente en Herejías (1887), libro incluido en Pompeyo Gener, Cosas de España. Herejías Nacionales. El Renacimiento de Cataluña. Barcelona: Juan Llorachs, 1903, pp. 107-139.

Gener, Pompeyo (1882). «Espagne», Le Livre. III (9), pp. 534-536.

Gener, Pompeyo (1883). «J. M. Bartrina», La Ilustración Ibérica. 30, 28.VII.1883, p. 6; 31, 4.VIII.1883, pp. 2-3, y 32, 11.VIII.1883, pp. 2-3. Compilado en Pompeyo Gener, Amigos y maestros. Contribución al estudio del espiritu humano a fines del siglo XIX. Barcelona: Maucci, 1915, pp. 295-311.

Givanel Mas, J[oan]. (1915). «El Quijote en el teatro (apuntes bibliográficos cervantinos)», Cervantes. 1, pp. 10-11, y 2, pp. 20-21.

Givanel i Mas, Joan (1916-1925). Catàleg de la Col-lecció Cervàntica formada per Isidro Bonsoms $i$ Sicart $i$ cedida per ell a la Biblioteca de Catalunya. Barcelona: Institut d'Estudis Catalans.

Gomis Blanco, Alberto y Jaume Josa Llorca (2009). «Los primeros traductores de Darwin en España: Vizcarrondo, Bartrina y Godínez», Revista de Hispanismo Filosófico. 14, pp. 43-60.

González Cuenca, Joaquín (ed.) (2006). Juan Valera y Nicolás Díaz de Benjumea. Sobre el sentido del Quijote. Madrid: Visor.

Gras i Elías, Francisco (1909). Siluetes d'escriptors catalans del sigle XIX. Barcelona: L'Avenç.

Gras i Elías, Francisco (1911). Bartrina (records intims). Barcelona: Llibreria Millà.

Gubernatis, A[ngelo]. de (1882). «Rassegna delle letterature straniere: Joaquín María Bartrina», Nuova Antologia di Scienze, Lettere ed Arti. 62, pp. 543-546.

Hartzenbusch, Juan Eugenio (1874). Las 1633 notas puestas por el Exmo. é Ilmo. Sr. D. Juan Eugenio Hartzenbusch a La primera edición del Ingenioso Hidalgo, reproducida por D. Francisco López Fabra con la foto-tipografía. Barcelona: Narciso Ramírez. 
Herreras, Domiciano (1980). Problemática de literatura española comparada. Proyección europea de la literatura y del pensamiento español. II. Málaga: Gráficas Urania.

Hunneus Gana, Jorge (1889). «Un párrafo sobre Bartrina», en íd., Estudios sobre España. Notas y proyectos para un libro. II. Santiago [de Cuba]: Rafael Jover, pp. 329-369.

Icaza, Francisco [de] A[sís]. de (1918). El «Quijote» durante tres siglos. Madrid: Renacimiento.

Jorba, Manuel (1984). Manuel Milà i Fontanals en la seva època. Trajectòria ideològica i professional. Barcelona: Curial.

Jorba, Manuel (1989). L'obra crítica i erudita de Manuel Milà i Fontanals. Barcelona: Curial - Publicacions de l'Abadia de Montserrat.

Jorba, Manuel (1991). Manuel Milà i Fontanals, crític literari. Barcelona: Curial - Publicacions de l'Abadia de Montserrat.

Littré, Émile (1875). Littérature et histoire. París: Didier.

Mainer, José-Carlos (1998). «Del corazón a la cabeza: sobre la poesía de Joaquín M. Bartrina», en Yvan Lissorgues y Gonzalo Sobejano (coords.), Pensamiento y literatura en España en el siglo XIX. Idealismo, positivismo, espiritualismo. Toulouse: Presses Universitaires du Mirail, pp. 109-122.

Mario, Luis (1992). Ciencia y arte del verso castellano. Miami: Universal.

Mario, Luis (2006). «Trágico origen de los versos de cabo roto», Prometeo Digital. Accesible en: <http://www.prometeodigital.org/FD_LISTATOTAL.htm>.

Marsillach, Joaquín (1880). «Joaquín María Bartrina», Día de Moda. 32, pp. 6-7.

Martí-Folguera, [Josep] (1874). Vibraciones. Barcelona: Imprenta de C. Verdaguer y Compañía.

Martí Folguera, J[osep]. (1883). «De todo», Revista del Centro de Lectura. 14, pp. 1-2.

Martí i Folguera, Josep (1920). «Lo Quimet Bartrina», Revista del Centre de Lectura de Reus. 18 , pp. 316-319.

Martínez Mata, Emilio (2001). «El sentido oculto del Quijote: el origen de las interpretaciones transcendentes, en Volver a Cervantes. Actas del IV Congreso Internacional de Cervantistas. Palma: Universitat de les Illes Balears. II, pp. 1201-1210.

Milà i Fontanals, Manuel (1869). Principios de teoría estética y literaria. Barcelona: Imprenta del Diario de Barcelona.

Milà i Fontanals, Manuel (1888). Obras completas. Tomo I. Tratados doctrinales de literatura. Barcelona: Imprenta de Álvaro Verdaguer.

Miró Folguera, J[osé]. (1878). «El escepticismo», El Eco del Centro de Lectura. 22, pp. $1-2$.

Miró Folguera, José (1880). «Bartrina», Las Circunstancias. 174, p. 1.

Miró Folguera, José ([1893]). El ratoncito. Barcelona: La Publicidad.

Montero Reguera, José (1997). «La crítica sobre Cervantes en el siglo XIX», en Carlos Reyero (dir.), Cervantes y el mundo cervantino en la imaginación romántica. Madrid: Consejería de Educación y Cultura - Dirección General de Patrimonio Cultural, pp. 29-43.

Montero Reguera, José (2005). El Quijote durante cuatro siglos. Lecturas y lectores. Valladolid: Universidad de Valladolid.

Moreno Claros, Luis Fernando (1994). «Schopenhauer en España (comentario bibliográfico)», Daimon. 8, pp. 203-232.

Moreno Nieto, Luis (2002). Cervantes en Toledo y Esquivias. Olías del Rey: Azacanes.

O'Connor, D. J. (1984). «Darwinism in Joaquín María Bartrina (1850-1880)», Kentucky Romance Quarterly. XXXII (4), pp. 393-404.

[Opisso, Alfredo] S. (1872). «Don Juan y don Quijote», El Ateneo Tarraconense de la Clase Obrera en homenaje de admiración y respeto al inmortal Miguel de Cervantes 
Saavedra al conmemorar el aniversario del fallecimiento del egregio autor del Ingenioso hidalgo don Quijote de la Mancha. Tarragona: Tipografía de F. Arís e Hijo, pp. $5-6$.

Opisso, Alfredo (1881). «Los dos símbolos. Don Juan y don Quijote», La Ilustración. 48, pp. 406-407.

Parada, Arturo (2004). «Arthur Schopenhauer (1788-1860), cervantista», Boletín de la Asociación de Cervantistas. I (2), pp. 5-11.

Pérez Capo, Felipe (1947). El Quijote en el teatro: Repertorio cronológico de 290 producciones escénicas relacionadas con la inmortal obra de Cervantes. Barcelona: Millà.

Pla, Josep (1969). «El senyor Miró i Folguera i el periodisme a Barcelona el 1919», en Josep Pla, Homenots. Primera sèrie. Obra completa. XI. Barcelona: Destino.

Pons y Umbert, Adolfo (1892). «Cartas catalanas. Carta I. Bartrina. A Vicente de Piniés», Revista Contemporánea. LXXXVIII, III, 407, pp. 297-301. Compilada, con el título de «Joaquín María Bartrina», en Adolfo Pons y Umbert, Vagando: Colección de artículos. Madrid: Imp. de los hijos de M. G. Hernández, 1903, pp. 10-15.

Rahola, Federico (1881). «Necrología», La Publicidad. 1378, pp. 1-2.

Rahola, Federico (1882). «Un pequeño comentario al Quijote», La Ilustración. 77, pp. 234-235.

Revilla, Manuel de la (2006). Obras completas. III. Madrid: UAM.

Riera, Carme (2002). La recepció del Tercer Centenari d'El Quixot a la premsa de Barcelona (1905). Barcelona: Reial Academia de Bones Lletres.

Riera, Carme (2005). El Quijote desde el nacionalismo catalán, en torno al tercer centenario. Madrid: Destino.

Rius, Leopoldo (1876). «Bibliografía cervántica», Cervantes. 3, pp. 81-84.

Rius, Leopoldo (1895-1904). Bibliografia crítica de las obras de Miguel de Cervantes Saavedra. I-III. Madrid: Librería de M. Murillo.

R[oca]. i R[oca]., J[osep]. (1880). «Joaquim Maria Bartrina», La Esquella de la Torratxa. 82 , pp. $1-2$.

Roca i Roca, J[osep]. (1916). Memòria biogràfica de Joaquim Maria Bartrina i d'Aixemús. Barcelona: Ajuntament Constitucional.

Rodríguez Solís, E[nrique]. (1900). «Joaquín María Bartrina», Heraldo de Madrid. 3554, p. [3].

Rossell Villasevil, José (1987). «Esquivias, Cervantes y el Quijote», en Homenaje de Esquivias a Cervantes. Toledo: Ayuntamiento de Esquivias, pp. 89-111.

Rovira, Pere (2002). Notas a Joaquín María Bartrina, Algo. Colección de poesías originales. Málaga: Puerta del Mar.

Santiago, Donald (1990). «La influencia de Arturo Schopenhauer en España desde finales del siglo XIX», en Antonio Heredia Soriano (coord.), Actas del VI Seminario de Historia de la Filosofia Española e Iberoamericana. Salamanca: Universidad de Salamanca, pp. 411-424.

Santiago, Donald (1993). «La recepción de Schopenhauer en España», Documentos A. Genealogía Científica de la Cultura. 6, pp. 146-155.

Savine, Albert (1882). «Les publications catalanes en 1881», Polybiblion. XV [I], pp. 439 449. Agradezco a Manuel Jorba que me facilitara este artículo, antes de que fuera localizable en Gallica.

Savine, Albert (1884). L'Atlantide: Poème traduit du catalan. De mossen Jacinto Verdaguer. París: Librairie Léopold Cerf.

Sedó Peris-Mencheta, Juan (1947). Ensayo de una bibliografía de miscelánea cervantina. Comedias, historietas, novelas, poemas, zarzuelas, etc. inspiradas en Cervantes o en sus obras. Barcelona: [s. e.]. 
Sotelo Vázquez, Adolfo (2001). «Schopenhauer, Zola y Clarín», en Adolfo Sotelo Vázquez, Perfiles de Clarín. Barcelona: Ariel, pp. 25-39.

Sotelo Vázquez, Adolfo (2014). «Joaquín María Bartrina y el prosaísmo poético», en Adolfo Sotelo Vázquez, De Cataluña y España. Relaciones culturales y literarias (1868-1960). Barcelona: Universitat de Barcelona, pp. 17-39.

Toda, Eduard (1920). «La joventut d'en Bartrina. Extracte de la conferència donada per Eduard Toda», Revista del Centre de Lectura. 19, pp. 344-350.

Tomàs, Margalida (2014). «Entorn de Joaquim M. Bartrina: estudis i edicions», Llengua \& Literatura. 24, pp. 155-290.

Tubino, Francisco M. (1872). Cervantes y el Quijote. Estudios críticos. Madrid: Librería de A. Durán.

Tubino, Francisco M. (2003 [1880]). Historia del Renacimiento literario contemporáneo en Cataluña, Baleares y Valencia, ed. Pere Anguera. Pamplona: Urgoiti Editores.

Tubino, Francisco M. (2005 [1880]). Historia del Renacimiento literario contemporáneo en Cataluña, Baleares y Valencia, pról. Josep M. Domingo. Lérida: Marius Torres.

Valera, Juan (1961). Obras completas. II. Madrid: Aguilar.

Valera Iglesias, Fernando (2007). «Realismo e idealismo en la recepción del Quijote. Una visión pendular», en Klaus-Dieter Ertler y Alejandro Rodríguez Díaz (eds.), El Quijote hoy. La riqueza de su recepción. Madrid - Frankfurt am Main: Iberoamericana Vervuert, pp. 43-77.

Vall [i Solaz], [Francesc] Xavier (2002). «Joaquim M. Bartrina i Àngel Guimerà», en Montserrat Corretger y Xavier Ferré (eds.), Joaquim M. Bartrina, entre les raons poètiques i les cientifiques. Reus: Arxiu Municipal de Reus, pp. 113-136.

Vall i Solaz, F[rancesc]. Xavier (2003). «L'escepticisme de Joaquim M. Bartrina a través d'"Epístola"», en Professor Joaquim Molas. Memòria, escriptura, història. II. Barcelona: Universitat de Barcelona, pp. 1153-1181.

Vall [i Solaz], F[rancesc]. Xavier (2005). «Un poema de Joaquim M. Bartrina en lloança de Frederic Soler i de la Renaixença», en Literatura i cultura reusenca del segle XIX. Reus: Centre de Lectura, pp. 125-179.

Vall i Solaz, F[rancesc]. Xavier (2008). «Bartrina i d'Aixemús, Joaquim Maria», en Àlex Broch y Manuel Jorba (dirs.), Diccionari de Literatura Catalana. Barcelona: Enciclopèdia Catalana, pp. 116-117.

Vall [i Solaz], [Francesc] Xavier (2012a). «L'evolucionisme en la literatura catalana», Anuari Verdaguer. 20, pp. 101-149.

Vall [i Solaz], [Francesc] Xavier (2012b). «The Phonograph in Barcelona (1877-1880): Technology and Ideological Controversies», Quaderns d'Història de l'Enginyeria. 12, pp. 255-286.

Zabalbeascoa, [José] A[ntonio]. (1968a). «El primer traductor de Charles R. Darwin en España», Filología Moderna. 31-32, pp. 269-275.

Zabalbeascoa Bilbao, José Antonio (1968b). La vida y las obras de Joaquín María Bartrina, José Manuel Blecua Teijeiro (dir.). Tesis doctoral. Universidad de Barcelona.

Recibido: 17 de mayo de 2018

Aceptado: 16 de junio de 2019 